Published in final edited form as:

Acta Biomater. 2018 April 15; 71: 24-36. doi:10.1016/j.actbio.2018.02.024.

\title{
Crystallinity of Hydroxyapatite Drives Myofibroblastic Activation and Calcification in Aortic Valves
}

\author{
Jennifer M. Richards ${ }^{1}$, Jennie A. M. R. Kunitake ${ }^{2}$, Heather B. Hunt ${ }^{2}$, Alexa N. Wnorowski ${ }^{1}$, \\ Debra W. Lin ${ }^{2}$, Adele L. Boskey ${ }^{\dagger, 3}$, Eve Donnelly ${ }^{2,3}$, Lara A. Estroff ${ }^{2,4}$, and Jonathan T. \\ Butcher $^{1}$ \\ ${ }^{1}$ Department of Biomedical Engineering, Cornell University, Ithaca, NY \\ ${ }^{2}$ Department of Materials Science and Engineering, Cornell University, Ithaca, NY \\ ${ }^{3}$ Musculoskeletal Integrity Program, Hospital for Special Surgery, New York, NY \\ ${ }^{4}$ Kavli Institute for Nanoscale Science, Cornell University, Ithaca, NY 14853, USA
}

\begin{abstract}
Calcific aortic valve disease (CAVD) is an inexorably degenerative pathology characterized by progressive calcific lesion formation on the valve leaflets. The interaction of valvular cells in advanced lesion environments is not well understood yet highly relevant as clinically detectable CAVD exhibits calcifications composed of non-stoichiometric hydroxyapatite (HA). In this study, Fourier transform infrared spectroscopic imaging was used to spatially analyze mineral properties as a function of disease progression. Crystallinity (size and perfection) increased with increased valve calcification. To study the relationship between crystallinity and cellular behavior in CAVD, valve cells were seeded into 3D mineral-rich collagen gels containing synthetic HA particles, which had varying crystallinities. Lower crystallinity HA drove myofibroblastic activation in both valve interstitial and endothelial cells, as well as osteoblastic differentiation in interstitial cells. Additionally, calcium accumulation within gels depended on crystallinity, and apoptosis was insufficient to explain differences in HA-driven cellular activity. The protective nature of endothelial cells against interstitial cell activation and calcium accumulation was completely inhibited in the presence of less crystalline HA particles. Elucidating valve cellular behavior postcalcification is of vital importance to better predict and treat clinical pathogenesis, and mineralcontaining hydrogel models provide a unique 3D platform to evaluate valve cell responses to a later stage of valve disease.
\end{abstract}

\section{Graphical abstract}

Address for correspondence: Jonathan T. Butcher, 304 Weill Hall, Cornell University, Ithaca, NY 14853, Office: 607-255-3575, Fax: 607-255-7330, jtb47@ cornell.edu.

†eceased 3 May 2017

Publisher's Disclaimer: This is a PDF file of an unedited manuscript that has been accepted for publication. As a service to our customers we are providing this early version of the manuscript. The manuscript will undergo copyediting, typesetting, and review of the resulting proof before it is published in its final citable form. Please note that during the production process errors may be discovered which could affect the content, and all legal disclaimers that apply to the journal pertain.

Disclosure:

The authors have no conflicts of interest to disclose. 


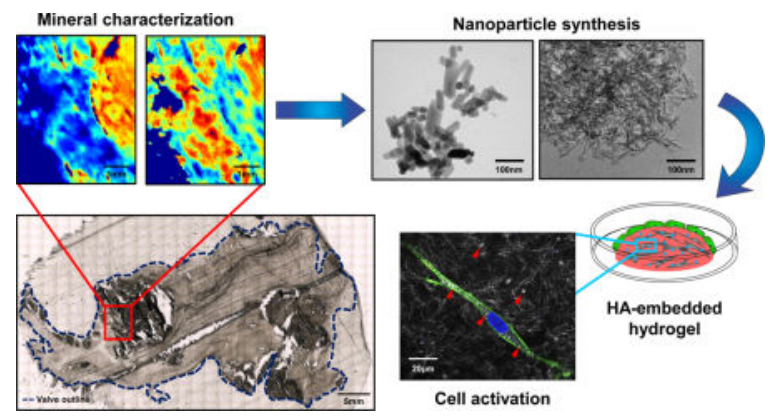

\section{Keywords}

Valve calcification; FTIR; hydroxyapatite nanoparticles; interstitial; endothelial; pathological biomineralization

\section{Introduction}

Calcific aortic valve disease (CAVD) is a degenerative pathology characterized by the progressive calcification of the valve leaflets. CAVD affects up to $2.5 \%$ of Americans and results in nearly 300,000 surgical interventions worldwide, signifying a considerable annual clinical burden[1]. Physicochemical studies have identified calcific nodules within diseased valve leaflets to be comprised of various phases of calcium phosphate, ranging from amorphous calcium phosphate particles to highly crystalline hydroxyapatite (HA; $\left.\mathrm{Ca}_{10}\left(\mathrm{PO}_{4}\right)_{6}(\mathrm{OH})_{2}\right)$ [2-7]. Unlike bone mineralization, which is a tightly regulated process[8], CAVD is an example of pathological mineralization[9,10], in which mineral deposition occurs in the normally fibrous valve leaflet matrix. Several techniques have been used to analyze the structure, chemical composition and crystallinity of the mineral that constitutes calcific nodules, including X-ray diffraction, Fourier transform infrared (FTIR) spectroscopy, Raman spectroscopy, and electron microscopy coupled with elemental analysis (SEM-EDS). Although these studies provide great insight into the bulk mineral characteristics[11-13], much less is known about the spatial heterogeneity of mineral distribution and composition throughout the valve.

CAVD is characterized by early endothelial injury or dysfunction[14,15] and the activation and potential differentiation of valve interstitial cells (VIC)[16]. Specifically, there is a shift of normally fibroblastic valve interstitial cells (VIC) to a more myofibroblastic phenotype[17,18] and/or an osteoblast-like phenotype[19]. Additionally, it has been shown that valve endothelial cells (VEC) can undergo an EMT-like transformation under inflammatory stimuli[20], and it has been postulated that activated forms of VEC may contribute to calcification[21]. There is evidence of both dystrophic calcification[22] caused primarily by apoptosis, as well as active mineralization of the leaflet matrix[23]. Finally, it is not known whether, or how, direct interaction of either VIC or VEC with existing mineralized matrix contributes to the activation and differentiation of either valve cell types.

Non-stoichiometric HA has been found in various pathological mineral deposits, such as kidney stones[24,25], microcalcifications associated with breast cancer[26-28], and calcified 
heart valves[6], and is the predominant mineral component of bone[29]. In efforts to understand how HA can regulate both normal and transformed cells, multiple studies have developed in vitro cell culture models using synthetic HA. The crystallinity (a measure of both crystal size and perfection[30]), shape, and composition of HA particles can be tuned by varying reaction conditions[31,32]. Studies using particles with well-defined properties have demonstrated property-dependent cellular responses such as adhesion, apoptosis, inflammatory responses, and osteogenic expression[33-37]. In CAVD, interstitial cells play distinct roles in initiating the calcification process of valves[38]; however, there is little understanding of the direct cellular consequences of existing HA particles proximal to valve cells. Use of synthetic HA particles could be a powerful tool to study how HA particles might drive activation of valve cells and further progress this degenerative disease.

In this work, we use results from an ex vivo characterization of human diseased heart valves to inform the design of an in vitro cell culture model to study the cellular response to a mineral-rich environment. Our first objective was to map spatial variations in mineral composition, structure, and distribution within valve leaflets with varying amounts of calcification (i.e., disease severity). Based upon this characterization, we identified carbonate content and crystallinity as two key variables that vary with disease severity. We then used that information to develop synthetic HA nanoparticles with well-defined materials properties to induce cell phenotype changes in vitro. By incorporating synthetically prepared HA particles of varying crystallinity into a previously described 3D collagen environment,[39] we investigated how the observed mineral properties in the ex vivo samples regulate interstitial and endothelial interactions and phenotypes. We found crystallinity-dependent differences in cellular uptake of HA particles. HA-driven apoptosis was also affected by crystallinity, and we discovered that smaller, less perfect HA drove higher matrix calcium accumulation, as well as increased myofibroblastic and osteoblastic responses in valve cells.

\section{Materials and Methods}

\subsection{Heart valve preparation}

Human diseased aortic valves were obtained from adults $(\mathrm{n}=5)$ undergoing planned, nonelective valve replacement surgery by Dr. Sanjay Samy at the Robert Packer Hospital (Sayer, PA). All procedures were approved by Institutional Review Boards at Cornell University and the Guthrie Clinic. The valves were retrieved directly from the operating room as soon as they were removed from the patient. They were transported from the hospital to the lab in PBS, and then fixed for 24 hours in 4\% paraformaldehyde (PFA, Sigma-Aldrich, Natick MA). One valve leaflet from each of the five different patients was randomly selected, photographed and then visually inspected for amount of valve calcification. Valve calcification was quantified as the area ratio of calcification, which was calculated as the area of calcified lesions divided by the total area of the valve.

\subsection{FTIR imaging and mineral parameter analysis of valves}

After overnight fixation in PFA, the 5 valve leaflets were serially dehydrated with graded alcohol solutions. Valves were halved in the median plane, and one half was embedded in 
poly(methyl methacrylate) (PMMA) (Polysciences, Warrington PA) and the other half was embedded in Spurr's resin (Sigma-Aldrich, Natick MA). Undecalcified 2- $\mu$ m-thick frontal sections were cut with a microtome (Leica Biosystems, Wetzlar, Germany). For each valve half, two to five regions of interest (ROIs) were selected and imaged. The ROIs spanned mineralized and non-mineralized portions of the valves and ranged in size from $\sim 0.12-0.16$ $\mathrm{mm}^{2}$. Each image was collected at a spatial resolution of $6.25 \mu \mathrm{m}$ and a spectral resolution range of $4 \mathrm{~cm}^{-1}$ over the range $750-2000 \mathrm{~cm}^{-1}$ using an infrared imaging system (Spotlight 300, PerkinElmer Instruments, Waltham MA). The FTIR images were analyzed using chemical imaging software (ISYS, Malvern Instruments, Malvern, UK). Spectra were truncated to a range of $800-1800 \mathrm{~cm}^{-1}$ and baseline corrected, and the spectral contribution from the embedding material (PMMA or Spurr's resin) was removed. The mean values of the following parameters[40] were calculated for each ROI: the mineral:matrix ratio (area ratio of the phosphate $\mathrm{v}_{1}\left[900-1200 \mathrm{~cm}^{-1}\right]$ and amide $\mathrm{I}$ [1585-1720 $\left.\mathrm{cm}^{-1}\right]$ peaks)[41,42], which provides a relative measure of mineral content in tissue; the mineral crystallinity (intensity ratio of $1030 \mathrm{~cm}^{-1}$ and $1020 \mathrm{~cm}^{-1}$ bands), which is related to crystal size and perfection[30]; and the carbonate:phosphate ratio (area ratio of the carbonate $\mathrm{v}_{2}$ (840-892 $\mathrm{cm}^{-1}$ ) and phosphate $\mathrm{v}_{1}$ ), which gives a metric of carbonate substitution in the apatite. FTIR parameters were calculated for each spectrum (pixel) within the ROI, and the mean of each parameter was calculated for each image. Means were plotted against the area ratio of calcification.

\subsection{HA particle synthesis and characterization}

Poorly crystalline (smaller, less perfect) HA particles (HA1) and larger, more perfect HA particles (HA2) were synthesized using an adaptation of our previously reported method[31]. Briefly, for both HA1 and HA2, ammonium phosphate dibasic solution $\left(\left(\mathrm{NH}_{4}\right)_{2} \mathrm{HPO}_{4}, 10 \mathrm{mM}, 200 \mathrm{~mL}\right)$ (Sigma-Aldrich, Natick MA) was added dropwise at a rate of $10 \mathrm{~mL} / \mathrm{min}$ to a solution of calcium nitrate $\left(\mathrm{Ca}\left(\mathrm{NO}_{3}\right)_{2} \bullet 4 \mathrm{H}_{2} \mathrm{O}, 10 \mathrm{mM}, 500 \mathrm{~mL}\right.$ ) (Riedelde Haën, Seelze, Germany) under rapid stirring in an ice bath $\left(4^{\circ} \mathrm{C}\right)$. Before combining, solutions were first balanced to $\mathrm{pH} 10$ using concentrated ammonium hydroxide $\left(\mathrm{NH}_{4} \mathrm{OH}\right.$, VWR, Radnor PA). The reaction was continuously stirred for three days in air at $20^{\circ} \mathrm{C}$. The resultant opaque suspension was allowed to settle for 30 minutes, after which white sediment separated from clear supernatant. The supernatant was then decanted such that the final volume containing the white sediment was approximately $1 / 4$ of the original volume. For HA1, the concentrated sediment was then washed two times with $\mathrm{NH}_{4} \mathrm{OH}(0.15 \mathrm{M})$, transferred to a hydrated dialysis bag (MWCO 6000-8000, CelluSep, Seguin TX), and dialyzed in $0.1 \mathrm{M}$ sodium hydroxide $(\mathrm{NaOH})$ over five days with $\mathrm{NaOH}$ solutions replaced every other day. For HA2, the concentrated solution was transferred to a pressure vessel (Parr Instrument Company, Moline IL), and aged in an oven (GS Blue M Electric, Watertown WI) at $180^{\circ} \mathrm{C}$ for 72 hours. Finally, the supernatant of the aged solution was decanted, and the remaining white sediment was washed two times with $\mathrm{NH}_{4} \mathrm{OH}(0.15 \mathrm{M})$, and dialyzed under the same conditions as HA1.

HA particles were examined by powder $\mathrm{x}$-ray diffraction (pXRD) (PAD-X theta-theta X-ray Diffractometer, CuKa $1.54 \AA$ A, accelerating voltage $40 \mathrm{kV}$, current $40 \mathrm{~mA}$, continuous scan, $1.0 \mathrm{deg} / \mathrm{min}$; Scintag Inc., West Palm Beach FL). Debye-Scherrer analysis was performed to 
estimate crystalline domain size using the $\{002\}$ peak of hydroxyapatite with an $\mathrm{Al} 2 \mathrm{O} 3$ standard to correct for instrumental broadening (Software: JADE 9, Materials Data, Inc.).

HA particles were also analyzed using Fourier transform infrared (FTIR) spectroscopy (Tensor 27 FT-IR Spectrometer, Bruker, Billerica MA). Dried particles were combined with $\mathrm{KBr}(0.06 \mathrm{mg}$ powder per $\mathrm{mg} \mathrm{KBr}$ ) and pressed into pellets to obtain FTIR spectra (spectral resolution $4.0 \mathrm{~cm}^{-1}, 64$ scans). Nanoparticle crystallinity was assessed from the splitting factor, calculated as the sum of the intensities at peaks $602 \mathrm{~cm}^{-1}$ and $563 \mathrm{~cm}^{-1}$ divided by the intensity of the minima between the two peaks, following Weiner and Bar-Yosef[43].

Transmission electron microscopy (TEM) (Tecnai T-12 Spirit, FEI, Hillsboro OR) was used for HA particle shape and morphology characterization. A drop of HA particles suspended in ethanol was evaporated onto carbon-coated copper grids (Electron Microscopy Sciences, Hatfield PA) and imaged with brightfield TEM. Long-axis lengths were measured manually from > 30 particles for both HA1 and HA2 in scale-calibrated TEM images using ImageJ[44]. The size ranges report the minimum to maximum lengths found among the measured particles. Ranges, rather than average particle sizes, were calculated due to the difficulty in discerning individual particles from TEM images of HA1 particles.

Elemental analysis was conducted to determine the calcium:phosphorus ratios of HA1 and HA2. For each sample, a quantity of powder (14.8 mgs for HA1, $14.7 \mathrm{mgs}$ for HA2) was dissolved in $1 \mathrm{~mL}$ of concentrated nitric acid for 1 hour. Following this, $20 \mathrm{~mL}$ of deionized water was added and, after 45 minutes, solutions were analyzed on an inductively coupled plasma optical emission spectrometer (Spectro Arcos axial viewed ICP-OES, SPECTRO Analytical Instruments Inc. a division of AMETEK ${ }^{\circledR}$ Materials Analysis, Kleve, Germany 2013).

\subsection{HA-collagen gel preparation}

Porcine aortic valve interstitial cells (VIC) and endothelial cells (VEC) were isolated as described previously[45] from valves donated by Shirk Meats (Dundee, NY). VEC were cultured in flasks coated with $50 \mu \mathrm{g} / \mathrm{mL}$ rat-tail collagen I (BD Biosciences, Billerica MA) at $37^{\circ} \mathrm{C}$ and $5 \% \mathrm{CO}_{2}$ in DMEM (Invitrogen, Carlsbad CA) supplemented with $10 \%$ FBS (Gemini Bio-Products, West Sacramento CA), 1\% penicillin-streptomycin (Invitrogen, Carlsbad CA), and $50 \mathrm{U} / \mathrm{mL}$ heparin (Sigma-Aldrich, Natick MA). VIC were cultured identically, but without the heparin supplement and the collagen flask coating. Purity of endothelial population was monitored via quantitative real-time PCR and immunofluorescent assessment. Only cultures with consistent CD31 and VE-cadherin expression, cobblestone morphology, and non-detectable aSMA expression were used. VEC and VIC cultures were used between passage four and six.

Collagen hydrogel constructs were prepared according to a previously described procedure, adapted for this work[39,46]. Collagen gels used in this study consisted of 1) VIC alone, 2) VEC alone, or 3) a VIC+VEC co-culture. Briefly, for VIC-containing gels, porcine aortic valve interstitial cells were suspended at 400,000 cells/mL in 3X DMEM with 10\% FBS (Gemini Bioproducts, West Sacramento CA), type I collagen (BD Biosciences, Billerica $\mathrm{MA}$ ), and $0.1 \mathrm{M} \mathrm{NaOH}$ for a final gel concentration of $2 \mathrm{mg} / \mathrm{mL}$. Gels with only VEC were 
seeded on a VIC-free gel. For the co-culture, the VIC-containing collagen constructs were allowed to gel for 1 hour at $37^{\circ} \mathrm{C}$ before subsequent seeding with a VEC monolayer at 50,000 cells/gel. HA particle- incorporated gels were achieved by adding HA dialyzed in 0.1 $\mathrm{M} \mathrm{NaOH}$ to the collagen gel solution, for a final concentration of either 0.1 or $0.25 \mathrm{mg} / \mathrm{mL}$. Particles were well mixed within the collagen solution via aspiration for complete incorporation of HA into collagen gels. VEC were added as detailed elsewhere[39] (Supplemental Figure S1). After 1 hour to allow for complete gelation, gels were cultured with DMEM (10\% FBS, 1\% penicillin-streptomycin) for up to 7 days.

\subsection{Confocal reflectance and HA particle distribution}

HA particle distribution within the collagen gels was assessed with a confocal microscope, (LSM700, Carl Zeiss Microscopy GmbH, Jena Germany) with a water-immersion 40X objective operated by Zeiss ZEN software. For confocal reflectance microscopy, a solid-state $405 \mathrm{~nm}$ laser illuminated the gel and backscattered light from the collagen fibers and aggregates of HA particles. Images were taken at four increments of $25 \mu \mathrm{m}$ within each gel, and at each depth, four separate scans were taken across the gel. Particles were counted via ImageJ[44] and organized in histograms based on number of particles per scanned image.

\subsection{Cellular uptake of HA particles}

To assess the uptake of HA particles into VIC, HA-incorporated gels were cultured for 24 hours, followed by a collagenase type-II (Worthington, Columbus $\mathrm{OH}$ ) digestion. Cells were re-plated and allowed to grow to confluence before being suspended in new VIC gels with no HA added to the collagen matrix. Pre- and post-collagenase digested gels were fixed with 4\% PFA overnight and stained with phalloidin (f-actin, 1:40) and Draq5 (DNA, 1:1000). Fluorescence and reflectance confocal imaging was performed to visualize cellular uptake of HA particles and particles were counted using ImageJ.

\subsection{Apoptosis}

To visualize cells undergoing apoptosis, collagen gel constructs were fixed with 4\% PFA and stained with a terminal deoxyribonucleotidyl transferase-mediated dUTP nick end labeling (TUNEL) assay kit (Invitrogen, Carlsbad CA). Following a 2-hour incubation, gels were counterstained with an anti-BrdU fluorescent antibody, phalloidin (f-actin), and Draq5 (DNA). Apoptosis was measured via the percentage of TUNEL-positive cells compared to total cell nuclei and normalized to control conditions.

\subsection{Real time RT-PCR}

Total RNA was extracted from homogenized hydrogels using the RNeasy Mini Kit (Qiagen, Hilden, Germany), which was then reverse transcribed into complementary cDNA using the iScript cDNA snythesis kit (Bio-Rad, Hercules CA), according to the manufacturer's instructions. Custom primers were obtained from Invitrogen and are listed in Supplemental Table 1. Quantitative real-time PCR was performed on all samples using SsoAdvanced SYBR green super mix (Bio-Rad, Hercules CA) and a CFX96 or MiniOpticon Real-Time PCR Detection System (Bio-Rad, Hercules CA). 


\subsection{Nitric oxide quantification}

Nitric oxide determination was achieved by measuring its stable decomposition product (nitrite) via the Griess Reagent Kit (ThermoFisher, Waltham MA). Media was transferred to a 96-well plate and combined with pre-mixed Griess Reagent. Samples were read on a spectrophotometric microplate reader at $548 \mathrm{~nm}$. Nitrites were normalized to control samples.

\subsection{Alizarin Red $S$ assay for matrix-bound calcium in collagen gel constructs}

Alizarin red S (ARS) dye binds to $\mathrm{Ca}^{2+}$ in a variety of forms, and can be used to visualize the accumulation of calcium within cell cultures [47-49]. The collagen gel constructs were fixed in 4\% paraformaldehyde overnight and washed 3X with PBS. Gels were then incubated with $40 \mathrm{nM}$ ARS dye for 20 minutes at room temperature. Unbound (soluble) dye was removed by washing in PBS overnight with gentle agitation. Immobilized ARS dye was released from the gels with $10 \%$ acetic acid, followed by neutralization with $10 \%$ ammonium hydroxide. ARS was quantified using absorbance spectroscopy at $405 \mathrm{~nm}$ wavelength. Cell-free gels with HA particles were used as controls to account for baseline levels of calcium.

\subsection{Statistical analysis}

For analysis of FTIR imaging data, linear models were used to explore the relationships between each parameter and area ratio of calcification. Each model contained the main effects of area ratio of calcification and embedding medium (PMMA or Spurr's resin), and the interaction between these two effects in order to determine whether the relationships were dependent on embedding method. Residual analyses were performed for each model to ensure that the linear model assumptions of normality and homogeneous variance were met.

All in vitro data are expressed as means \pm standard error, with at least three independent experiments per treatment. Analysis of variance with Tukey's post-hoc test was used to compare differences between means. All analyses were performed using JMP (Version 13, SAS Institute Inc.) and p-values $<0.05$ were considered statistically significant.

\section{Results}

\subsection{Crystallinity and carbonate content vary with valve calcification}

Five valves with increasing area ratios of calcification were analyzed to evaluate differences in mineralized tissue composition as a function of disease progression (Figure 1A, B). FTIR imaging was used to chemically map the distribution of matrix components within the valves. The main components of the valve tissue were identified from characteristic vibrational modes corresponding to apatite (phosphate) and collagen (amide I) (See Supplemental Figure S2C for phosphate and amide I peak positions)[2,12,13,50]. FTIR parameters, previously established to analyze both physiological and dystrophic systems of apatitic biomineralization[51,52], were calculated for each image. Though valves were embedded in both PMMA and Spurr's resin, data from both embedding materials were pooled because the interaction between area ratio and embedding material was not statistically significant for any of the parameters $(p=0.9200$ for crystallinity, $p=0.8797$ for 
carbonate:phosphate, $p=0.4391$ for mineral:matrix). An example ROI with corresponding FTIR parameter means is shown for a severely calcified valve (Figure 1B, C, distribution histograms Supplementary Figure S2A). The mineral:matrix means ranged from 3.5 to 23.7, crystallinity means ranged from 0.99 to 1.29 , and carbonate:phosphate means ranged from 0.0071 to 0.014 . Bimodal distributions were observed for mineral:matrix ratio (32\% of all ROIs, example shown in Supplementary Figure S2A) and crystallinity (25\% of all ROIs) parameters, though bimodal distributions for both mineral:matrix and crystallinity never occurred for the same ROI.

In addition, relationships among FTIR parameters and the valve area ratios of calcification were examined with regression analyses (Figure 2). Carbonate:phosphate decreased with area ratio of calcification $(p=0.0069)$ and crystallinity increased with area ratio of calcification ( $p=0.0138$ ) (Figure 2A, B). Additionally, crystallinity decreased with carbonate:phosphate ratio $(p<0.0001)$ (Figure 2C). The relationship between mineral:matrix and area ratio of calcification was not statistically significant (Supplementary Figure $\mathrm{S} 3, p=0.627)$.

\subsection{Synthetic HA particles model diseased aortic valve mineral properties}

Based upon the differences in mineral properties within calcified valves identified by FTIR imaging, two populations of HA particles with different crystallinities were synthesized. These particles were then incorporated into collagen gel constructs and used to evaluate cellular responses to a mineral-rich environment. Established procedures were used to synthesize less crystalline (HA1) and more crystalline (HA2) particles[31]. The particles were characterized by powder ICP-OES, x-ray diffraction (pXRD), FTIR, and TEM (Supplementary Figure S4). Elemental analysis by ICP-OES shows that both HA1 and HA2 have calcium:phosphorus ratios of 1.7 , consistent with hydroxyapatite, with no differences in composition detected. The pXRD pattern of HA1 had fewer peaks than the pattern for HA2, and the peaks for HA1 were broader than those of HA2, which is consistent with HA1 being smaller and less perfect than HA2 (Supplementary Figure S4C). A Debye-Scherrer analysis of the $\{002\}$ peak estimated the particle lengths of HA1 to be $\sim 23 \pm 1.9 \mathrm{~nm}$ and $\mathrm{HA} 2$ to be $\sim 71 \pm 5.7 \mathrm{~nm}$ long. The FTIR data confirms that HA2 is more crystalline than HA1, based upon the $\mathrm{v}_{4}$ phosphate splitting factor, which is known to increase with increasing crystallinity[43]. The splitting factor for HA1 particles was 3.7 versus 4.8 for $\mathrm{HA} 2$ particles. Additionally the crystalline $\mathrm{OH}$ vibration is more prominent in the HA2 spectrum[53] (Supplementary Figure S4D). TEM images show that both types of particles have rod-like morphologies. Measurements of the long axes of these particles confirm the size differences between the smaller HA1 $(\sim 15-40 \mathrm{~nm})$ and larger HA2 ( 22-150 nm) synthetic HA variants (Figure 3A, B insets), consistent to what has been shown previously with a similar synthetic route[54].

\subsection{Crystallinity alters HA particle aggregate distribution within collagen gels}

The dialyzed HA particles in $1 \mathrm{M} \mathrm{NaOH}$ were used to neutralize acidic collagen solutions to trigger gelation. Confocal reflectance microscopy revealed HA particle aggregates to be distributed throughout the collagen matrix. Particles were incorporated into collagen gels at two concentrations $(0.1 \mathrm{mg} / \mathrm{mL}$ and $0.25 \mathrm{mg} / \mathrm{mL})$. The less crystalline HA1 particles had 
much smaller aggregates than the HA2 particles[54], but both particle types were well dispersed through the entire thickness of the gels (Figure 3A, B). HA1 particle aggregates had qualitatively normal distributions throughout the full thickness of the gel, and as expected, the $0.25 \mathrm{mg} / \mathrm{mL}$ HA1 gel had an increased presence of aggregates per image (17 \pm 0.6 aggregates in $0.1 \mathrm{mg} / \mathrm{mL}$ vs. $43 \pm 1.4$ aggregates in $0.25 \mathrm{mg} / \mathrm{mL}$ gels) (Figure $3 \mathrm{~A}$ ).

The more crystalline HA2 particles had similar increases in aggregate number with concentration ( $23 \pm 0.8$ aggregates in $0.1 \mathrm{mg} / \mathrm{mL}$ vs. $47 \pm 2$ aggregates in $0.25 \mathrm{mg} / \mathrm{mL}$ gels) (Figure 3B). Preliminary data revealed that altering particle concentration had little effect on cellular response (Supplemental Figure S5); therefore, the remainder of this paper will focus on differences between HA type within the collagen hydrogels, rather than on concentration. All subsequent data focus on gels with either HA1 or HA2 incorporated at a concentration of $0.25 \mathrm{mg} / \mathrm{mL}$.

\subsection{VIC uptake less crystalline HA particle aggregates more readily than VEC}

Valve interstitial cells (VIC) were cultured in collagen gels containing HA1 or HA2. After 24 hours of culture, both HA1 and HA2 particle aggregates were clearly visible throughout the collagen matrix as visualized with confocal microscopy. In addition, a combination of fluorescent and reflectance imaging revealed particles within the cytoplasm of interstitial cells and/or closely associated with cell membranes (Figure 4A). To ensure that HA particles were dispersed within the VIC, gels were digested using type-II collagenase and VIC were harvested via centrifugation. When VIC were seeded within new collagen gels, free of HA particles, they were re-examined and found to still have particle aggregates within the cytoplasm (Figure 4B). The less crystalline HA1 particles had significantly higher uptake within the cells as compared to the more crystalline HA2 particles ( $38 \pm 3.5$ vs. $26 \pm 3.0$ aggregates, $p<0.05$ respectively) (Figure 4C).

\subsection{HA particle crystallinity may regulate apoptosis}

To examine if apoptosis was regulated by HA crystallinity, a TUNEL apoptosis assay was performed (Figure 5). After 7 days of culture, the number of apoptotic (green) cells in VIC gels cultured with HA1 particles was significantly higher than those in control conditions $(10.0 \% \pm 1.4 \%$ vs. $2.9 \% \pm 0.3 \%$, respectively). HA2 particles did not induce an apoptotic response relative to control for VIC cultures (Figure 5A). VEC-only gels had no significant differences in apoptosis from control conditions when cultured with HA1 and HA2 (Figure 5B). VIC+VEC co-cultures had similar apoptotic responses to HA1 and HA2 particles to the VIC-only cultures, in that only the HA1 VIC+VEC gels had significantly higher apoptosis as compared to control conditions (10.9\% $\pm 2.9 \%$ vs. $6.3 \% \pm 0.4 \%$, respectively) (Figure 5C). There were no differences in apoptosis between VEC and VIC in each co-culture condition.

\subsection{HA crystallinity may regulate myofibroblastic activation and osteoblastic differentiation}

Myofibroblastic activation was measured via expression of aSMA. VIC-only gels cultured for 7 days with HA1 particles expressed significantly higher aSMA (3.07 \pm 0.25 fold vs. HA-free controls). However, HA2 VIC-only gels, while higher than controls $(2.11 \pm 0.16$ fold), expressed less aSMA than gels cultured with the less crystalline HA1 particles (Figure 6A). This trend continued with VEC-only gels, with HA1 incorporated gels 
expressing significantly higher aSMA $(6.87 \pm 2.87$ fold $)$ vs. control, and HA2 gels, while higher (1.78 \pm 0.27 fold), was closer to control levels (Figure 6A). VIC+VEC co-cultures combined with HA1 particles additionally expressed higher aSMA levels $(4.32 \pm 0.25)$ compared to control cultures, while expression in cultures with HA2 particles was not statistically different from that of control cultures (Figure 6A). These data demonstrate that less crystalline particles drive myofibroblastic activation in both VIC and VEC cultures.

Similarly, 7-day cultures with HA particles drove an osteoblastic response in VIC and VIC +VEC cultures. In VEC-only gels, cultures with either HA1 or HA2 particles did not significantly affect expression of either Runx2 or osteopontin (OPN), except for Runx2 expression in VEC with HA2 particles ( $0.12 \pm 0.01$ fold vs. controls) (Figure 6B, C). Runx2 expression, while not statistically significant, was upregulated in VIC-only gels with HA1 particles (1.46 \pm 0.54 fold vs. control), while Runx 2 expression in cultures with HA2 particles did not differ from control cultures (Figure 6B). However, in VIC+VEC co-cultures with HA1 particles, Runx 2 was significantly increased ( $4.44 \pm 1.02$ fold vs. controls), and to a much lesser degree in cultures with HA2 particles (1.82 \pm 0.13 fold vs. controls) (Figure 6B). OPN expression was higher in VIC-only gels cultured with HA1 particles $(2.55 \pm 0.30$ fold vs. controls) and HA2 particles (1.69 \pm 0.11 fold vs. controls), though to a lesser degree in the latter (Figure 6C). In VIC+VEC co-cultures, only cultures with HA1 particles had higher OPN expression ( $2.67 \pm 0.35$ vs. controls) (Figure 6C). Collectively, these data reveal that less crystalline HA has a robust effect on myofibroblastic activation in VIC and VEC, and osteoblastic differentiation in VIC, while more crystalline particles have a lesser effect on cellular activation and differentiation.

\subsection{HA properties regulate endothelial activity}

VIC+VEC cultures were examined for endothelial activity to determine the loss of protection against VIC activation and differentiation. VCAM1 expression was significantly higher in the gels with less crystalline HA ( $2.35 \pm 0.27$ fold vs. controls) (Figure 7A), which indicates a potential inflammatory response by the VEC to the HA particles. Interestingly, eNOS expression was also increased in cultures with the less crystalline particles (3.02 \pm 0.68 fold vs. controls) (Figure 7B). In addition, nitric oxide in the co-culture media was analyzed, and it was found that there was increased nitric oxide in the less crystalline HA gels ( $1.06 \pm 0.075$ relative to controls), although this increase was not statistically significant (Figure 7C).

\subsection{Calcium accumulation in collagen gel constructs related to HA crystallinity}

An Alizarin Red S (ARS) assay was used to determine if cells cultured in 3D gels with incorporated HA particles would induce an increase in matrix-bound calcium within the collagen gels. All gels were normalized to cell-free HA-incorporated gels to account for baseline ARS bound to the HA nanoparticles, and then compared to their respective cell controls. HA1-gels with VIC-only, VEC-only and VIC+VEC had significantly increased ARS staining when compared to controls (Figure 8A). VIC-only gels measured $2.73 \pm 0.488$ ARS absorbance, VEC-only gels measured $2.32 \pm 0.06$ and VIC+VEC co-cultures measured $3.08 \pm 0.41$, relative to their HA-free controls (Figure 8B). Interestingly, after 7 days of culture with the more crystalline HA2 particles, VEC-only and VIC+VEC co-cultures had 
no more ARS staining than the controls ( $1.54 \pm 0.73$ and $1.16 \pm 0.03$, respectively). While the HA2 VIC-only gels were statistically higher than the control level $(1.24 \pm 0.02)$, this level of ARS staining was drastically lower than that of its HA1 counterpart (Figure 8B).

\section{Discussion}

Calcific aortic valve disease is a pathology characterized by the progressive degeneration of valve function due to the active deposition of mineralized lesions within the valve leaflet tissue[55]. While previous studies have reported that calcified valve lesions contain apatite[2,12], the crystallinity (i.e., size and perfection) of this mineral had not been spatially mapped within valves, nor were the functional consequences of changing mineral properties assessed in vitro. Our results demonstrate that in diseased human valves, apatite crystallinity increased and carbonate content decreased with increasing valve calcification. For this analysis, we have assumed that carbonated apatite is the dominant phase; evidence of several other phases has been reported though these are generally considered to be either precursors or less prevalent than apatite $[5,13,56]$. The range of mean crystallinity values from calcified valve ROIs (0.99-1.29) was within that reported for human osteonal bone[57] and carbonate:phosphate means (0.0071-0.014) were also consistent with those found in bone[57,58]. The crystallinity parameter has been interpreted as a metric of mineral maturity in bone, in which a more mature mineral particles are larger and contain fewer substitutions and defects[30,57,59]. The increasing apatite crystallinity found here along with a corresponding decrease in carbonate substitution with increase of valve calcification could suggest the presence of more mature mineral found in later stages of CAVD. However, it could also be indicative of an increasing proportion of a more crystalline phase of mineral as reported elsewhere[6,60].

The mineral:matrix means were generally higher and spanned a larger range (3.5-23.7) than means taken from bone ( $4.0-5.0$ in human osteonal bone[57]). $92 \%$ of the valve regions analyzed had mineral:matrix means greater than 5 , while $42 \%$ had mean values above 10 , closer to that of enamel ( 11 for mice[61]). High values correspond to spectra with a broadened phosphate peak complex and/or diminished amide I protein component (Supplementary Fig. S2C), consistent with recent electron microscopy results that identify a poorly crystalline, compact, dense mineral phase free of collagen fibers[60]. In our study, no significant relationship between mineral:matrix ratio and valve calcification was detected.

These results, taken together with the frequency of bimodal distributions within images in this sample set (32\% for mineral:matrix, $25 \%$ for crystallinity) suggests there are multiple types of mineralized regions including areas with precursors or other mineral phases[5,13,56], highly mineralized regions[62], and/or regions with more or less mature mineral[22,30,57,59]. The presence of multiple types of mineralized material could have several explanations, including non-homogeneous distribution of non-collagenous matrix components (e.g., elastin) with varying activities towards mineral deposition and/or multiple formation mechanisms of the mineral.

Importantly, the trends and complexities found in the FTIR mapping analysis of human heart valves warrant a better understanding of the interplay between mineral properties and 
cellular behavior[63]. While cellular behavior changes in response to osteogenic stimuli in the form of phosphate salts[23,64,65], matrix stiffness changes[66], and growth factor exposure[67,68], there are no current models to investigate cell-mineral interactions in response to changing HA particle properties. In this study, we used synthetic hydroxyapatite particles with differing crystallinities in conjunction with our previously reported 3D hydrogel culture system[39] to elucidate direct effects of apatite particle properties on cellular behavior. We incorporated and evenly distributed dialyzed particle aggregates into a collagen gel, which ensured maximum contact with valve interstitial and endothelial cells.

Our study shows that both interstitial and endothelial cells were activated in the presence of smaller, less perfect particles (HA1), while the larger, more perfect particles (HA2) had little to no effect on the myofibroblastic nature of the cells. Interestingly, the presence of VEC did not mitigate VIC activation, as we previously reported when cultured in osteogenic media[39]. This loss of protection could be in part due to an inflammatory response, as indicated by the increased VCAM1 expression. Additionally, the HA1-induced increase of eNOS mRNA expression combined with no change in NO secretion points to a net effect of a complex system. One possibility is an eNOS uncoupling effect, which inhibits the ability of VEC to protect against calcification, although future studies would be required for confirmation[21]. Similarly, cultures with less crystalline HA caused osteoblastic differentiation in VIC, as measured by Runx 2 and OPN expression, which was again not reduced by the presence of VEC in the co-culture. These results demonstrate that the presence of HA1 particles within the collagen hydrogel mitigate the protective effects that VEC have on VIC in 3D cultures. Finally, ARS staining suggests that calcium accumulation within the collagen matrix was influenced by HA crystallinity, as it was the less crystalline HA1-embedded gels that stained more heavily with ARS, while there was little to no increase in ARS staining within the HA2-embedded gels.

Our study demonstrates that less crystalline HA particle aggregates more strongly induce cellular apoptosis, although the total percentage of apoptosis was minimal throughout each condition. Dystrophic calcification, by definition, is associated with necrotic or apoptosisdriven calcium deposition by cells[69]. While apoptosis is present in regions of calcified valve leaflets, there are also regions with active pathological ectopic calcification[67,70]. Some 2D studies have shown that nodules, which have apoptotic cores, form in response to osteogenic stimuli[23,71]. However, our 3D study reveals that not only were the particles at our dosage not cytotoxic[72-74], there was very little apoptosis-driven calcification of the collagen gels, indicating that calcium accumulation within the gel was instead occurring through myofibroblastic activation and osteogenic differentiation mechanisms.

As is common with particles of this size[75], there was higher uptake of smaller, less perfect HA1 particle aggregates within interstitial cells. Uptake of nanoparticles are typically due to variations of endocytosis[76], but further study is necessary to determine the specific mechanism behind cellular uptake of our HA nanoparticles. The observed difference in HA uptake may contribute to the active calcium immobilization by the cells and the higher myofibroblastic activation and osteoblastic differentiation in the case of the HA1 particles. The surface to volume ratio for smaller particles is much higher, which could account for this difference in cell response. This difference would not be due to the varying solubility of 
HA particles as previous work determined them to be negligibly soluble in a cell culture environment[31], but could be due to cellular interaction with particle or aggregate surfaces. In a separate study with the same synthetic particles, both the amount of adsorbed fibronectin, as well as the conformation (i.e., compact vs. extended) were found to vary as a function of particle crystallinity, which suggests that proteins adsorbed on HA1 versus HA2 particle surfaces will present different binding sites for adhesion and activation of cells[54]. Other studies have postulated that interactions of cells with surfaces of HA particles are mediated by integrins on cell membranes[77,78]. HA particle uptake has been shown to induce activation in endothelial cells, with increased IL-6 production[79], as well as induction of osteogenic differentiation in human adipose-derived stem cells[80].

Additionally, it has been established that crystals of a differing size can affect cellular response[81]. Our study provides insights regarding cellular response to the presence of preformed HA particles of varying crystallinity within a 3D culture model that mimics a pathological calcified valve matrix.

The in vitro model developed in this work represents a critical starting point for this line of inquiry. However, there were some limitations to this study that should be highlighted. Macroscopic gross inspection of the valve calcification (i.e., area ratio of calcification) is a semi-quantitative assessment that is akin to what could happen in surgery. We showed that certain aspects of mineralization (i.e., crystallinity) correlated with visual calcification of valve leaflets. While one leaflet may have a larger, less mineralized lesion, and another have a smaller, more mineralized lesion, the correlation across valves supports that more calcification (grossly determined) correlated with advanced lesions. While we acknowledge that the gross inspection was a limitation of this study, future work could focus on a more clinically-relevant characterization of the valves before being tested for variability within the mineralized portions of the valves. We were also limited to using porcine cells in our models of valve disease, as porcine cells are well characterized and less variable, enabling the focus of this work to be on the effect of HA on cell activity. Future work could focus on human cell characterization (healthy and diseased) and the development of a human cell model. Additionally, future studies could focus on the actual genesis and growth of HA within the matrix, giving important mechanistic insight into why the observed changes are occurring.

Our FTIR analysis of diseased human valve tissue reveals that earlier stages of valve mineralization have lower apatite crystallinity. This result aligns with our in vitro findings that less crystalline HA particles drive cellular activation and possibly, calcification, via osteoblastic differentiation and calcium accumulation. These findings collectively demonstrate that the presence and nature of calcification in aortic valve tissue can independently drive valve pathogenesis in ways that mimic progressive calcific degeneration in vivo. The 3D in vitro culture platform developed and implemented herein provides a unique test bed for elucidating clinically important but poorly understood molecular and cellular events governing calcific progression, which are critical for identifying therapeutic compounds that could slow or reverse this process as valve calcification is already present when clinical symptoms present[82]. 


\section{Supplementary Material}

Refer to Web version on PubMed Central for supplementary material.

\section{Acknowledgments}

We acknowledge Dr. Sanjay Samy and the Guthrie Clinic in Sayre, PA for providing the diseased human valve tissue, Dr. Amy Blakeley for initial mineral analysis of valve tissue and particle preparation, Laura Miller for the preparation and FTIR imaging of valves, David Diaz for preliminary analysis of FTIR images, and Lynn M. Johnson from the Cornell Statistical Consulting Unit for assistance on FTIR data statistical analysis. We also wish to thank Dr. Michael Rutzke for carrying out the ICP-OES experiments and assisting with the analysis.

Funding:

This work was supported by the NIH (R21 HL118672, HL128745), NSF (CBET-955172), and the Hartwell Foundation, as well as the Cornell CLC Imaging Core and CCMR electron microscopy and x-ray diffraction facilities. CCMR facilities are supported by the National Science Foundation under Award Number DMR-1719875.

\section{Non-standard abbreviations and acronyms}

aSMA alpha-Smooth Muscle Actin

ARS Alizarin Red S

eNOS Endothelial nitric oxide synthase

FTIR Fourier Transform Infrared Spectroscopy

HA Hydroxyapatite

KBr Potassium Bromide

$\mathbf{N H}_{4} \mathbf{O H}$ Ammonium hydroxide

OGM Osteogenic Media

OPN Osteopontin

Runx2 Runt-Related Transcription Factor 2

TEM Transmission Electron Microscopy

VCAM1 Vascular Cell Adhesion Molecule 1

VEC Valve Endothelial Cell

VIC Valve Interstitial Cell

XRD X-ray Diffraction

\section{References}

1. Mozaffarian D, Benjamin EJ, Go AS, Arnett DK, Blaha MJ, Cushman M, de Ferranti S, Després JP, Fullerton HJ, Howard VJ, Huffman MD, Judd SE, Kissela BM, Lackland DT, Lichtman JH, Lisabeth LD, Liu S, Mackey RH, Matchar DB, McGuire DK, Mohler ER, Moy CS, Muntner P, Mussolino ME, Nasir K, Neumar RW, Nichol G, Palaniappan L, Pandey DK, Reeves MJ, Rodriguez CJ, Sorlie PD, Stein J, Towfighi A, Turan TN, Virani SS, Willey JZ, Woo D, Yeh RW, Turner MB. 
Heart disease and stroke statistics-2015 update: a report from the American Heart Association. Circulation. 2015; 131:e29-e322. DOI: 10.1161/CIR.0000000000000152 [PubMed: 25520374]

2. Prieto RM. Study on the structure and composition of aortic valve calcific deposits. etiological aspects. J Biophys Chem. 2011; 2:19-25. DOI: 10.4236/jbpc.2011.21003

3. Tomazic BB, Edwards WD, Schoen FJ. Physicochemical characterization of natural and bioprosthetic heart valve calcific deposits: Implications for prevention. Ann Thorac Surg. 1995; 60:S322-S327. DOI: 10.1016/0003-4975(95)00205-Y [PubMed: 7646181]

4. Cottignoli V, Cavarretta E, Salvador L, Valfré C, Maras A. Morphological and chemical study of pathological deposits in human aortic and mitral valve stenosis: A biomineralogical contribution. Patholog Res Int. 2015; :1-14. DOI: 10.1155/2015/342984

5. Pilarczyk M, Czamara K, Baranska M, Natorska J, Kapusta P, Undas A, Kaczor A. Calcification of aortic human valves studied in situ by Raman microimaging: Following mineralization from small grains to big deposits. J Raman Spectrosc. 2013; 44:1222-1229. DOI: 10.1002/jrs.4352

6. Bertazzo S, Gentleman E, Cloyd KL, Chester AH, Yacoub MH, Stevens MM. Nano-analytical electron microscopy reveals fundamental insights into human cardiovascular tissue calcification. Nat Mater. 2013; 12:576-83. DOI: 10.1038/nmat3627 [PubMed: 23603848]

7. Hutcheson JD, Goettsch C, Bertazzo S, Maldonado N, Ruiz JL, Goh W, Yabusaki K, Faits T, Bouten C, Franck G, Quillard T, Libby P, Aikawa M, Weinbaum S, Aikawa E. Genesis and growth of extracellular-vesicle-derived microcalcification in atherosclerotic plaques. Nat Mater. 2016; 15:335343. DOI: 10.1038/nmat4519 [PubMed: 26752654]

8. Reznikov N, Steele JAM, Fratzl P, Stevens MM. A materials science vision of extracellular matrix mineralization. Nat Rev Mater. 2016; 1:16041.doi: 10.1038/natrevmats.2016.41

9. Poloni LN, Ward MD. The materials science of pathological crystals. Chem Mater. 2014; 26:477495. DOI: $10.1021 / \mathrm{cm} 402552 \mathrm{v}$

10. Bazin D, Daudon M, Combes C, Rey C. Characterization and Some Physicochemical Aspects of Pathological Microcalcifications. Chem Rev. 2012; 112:5092-5120. DOI: 10.1021/cr200068d [PubMed: 22809072]

11. Gilinskaya LG, Grigorieva TN, Okuneva GN, Vlasov YA. Investigation of pathogenic mineralization on human heart valves. 1. Chemical and phase composition. J Struct Chem. 2003; 44:622-631. DOI: 10.1023/B:JORY.0000017938.42883.9f

12. Tomazic BB. Physicochemical principles of cardiovascular calcification. Z Kardiol. 2001; 80:6880.

13. Mikroulis D, Mavrilas D, Kapolos J, Koutsoukos PG, Lolas C. Physicochemical and microscopical study of calcific deposits from natural and bioprosthetic heart valves. Comparison and implications for mineralization mechanism. J Mater Sci Mater Med. 2002; 13:885-889. DOI: 10.1023/A: 1016556514203 [PubMed: 15348554]

14. Poggianti E, Venneri L, Chubuchny V, Jambrik Z, Baroncini LA, Picano E. Aortic valve sclerosis is associated with systemic endothelial dysfunction. J Am Coll Cardiol. 2003; 41:136-41. [PubMed: 12570956]

15. Butcher JT, Nerem RM. Valvular endothelial cells and the mechanoregulation of valvular pathology. Philos Trans R Soc Lond B Biol Sci. 2007; 362:1445-1457. DOI: 10.1098/rstb. 2007.2127 [PubMed: 17569641]

16. Rajamannan NM, Evans FJ, Aikawa E, Grande-Allen KJ, Demer LL, Heistad DD, Simmons CA, Masters KS, Mathieu P, O'Brien KD, Schoen FJ, Towler DA, Yoganathan AP, Otto CM, Calcific aortic valve disease: not simply a degenerative process: a review and agenda for research from the National Heart and Lung and Blood Institute Aortic Stenosis Working Group. Executive summary: Calcific aortic valve disease-2011 update. Circulation. 2011; 124:1783-1791. DOI: 10.1161/ CIRCULATIONAHA.110.006767 [PubMed: 22007101]

17. Gu X, Masters KS. Role of the Rho pathway in regulating valvular interstitial cell phenotype and nodule formation. Am J Physiol Heart Circ Physiol. 2011; 300:H448-H458. DOI: 10.1152/ ajpheart.01178.2009 [PubMed: 21131478]

18. Merryman WD, Lukoff HD, Long RA, Engelmayr GC, Hopkins RA, Sacks MS. Synergistic effects of cyclic tension and transforming growth factor-beta1 on the aortic valve myofibroblast. Cardiovasc Pathol. 2007; 16:268-276. DOI: 10.1016/j.carpath.2007.03.006 [PubMed: 17868877] 
19. Rajamannan NM, Subramaniam M, Rickard D, Stock SR, Donovan J, Springett M, Orszulak T, Fullerton DA, Tajik AJ, Bonow RO, Spelsberg T. Human aortic valve calcification is associated with an osteoblast phenotype. Circulation. 2003; 107:2181-2184. DOI: 10.1161/01.CIR. 0000070591.21548.69 [PubMed: 12719282]

20. Farrar EJ, Butcher JT. Heterogeneous susceptibility of valve endothelial cells to mesenchymal transformation in response to TNFa. Ann Biomed Eng. 2014; 42:149-61. DOI: 10.1007/ s10439-013-0894-3 [PubMed: 23982279]

21. Farrar EJ, Huntley GD, Butcher J. Endothelial-derived oxidative stress drives myofibroblastic activation and calcification of the aortic valve. PLoS One. 2015; 10:e0123257.doi: 10.1371/ journal.pone.0123257 [PubMed: 25874717]

22. Mohler ER, Gannon F, Reynolds C, Zimmerman R, Keane MG, Kaplan FS. Bone formation and inflammation in cardiac valves. Circulation. 2001; 103:1522-1528. DOI: 10.1161/01.CIR. 103.11.1522 [PubMed: 11257079]

23. Chen J, Peacock JR, Branch J, David W. Merryman, Biophysical analysis of dystrophic and osteogenic models of valvular calcification. J Biomech Eng. 2015; 137:20903.doi: $10.1115 / 1.4029115$

24. Kodati VR, Tomasi GE, Turumin JL, Tu AT. Raman spectroscopic identification of phosphate-type kidney stones. Appl Spectrosc. 1991; 45:581-583. DOI: 10.1366/0003702914336859

25. Coe FL, Parks JH, Asplin JR. The pathogenesis and treatment of kidney stones. N Engl J Med. 1992; 327:1141-1152. [PubMed: 1528210]

26. Kunitake J, Choi S, Nguyen J, Lee M, He F, Sudilovsky D, Morris P, Jochelson M, Hudis C, Muller D, Fratzl P, Fischbach C, Masic A, Estroff L. Correlative imaging reveals physicochemical heterigeneity of microcalcifications in human breast carcinomas. J Struct Biol. 2017 in press.

27. Baker R, Rogers KD, Shepherd N, Stone N. New relationships between breast microcalcifications and cancer. Br J Cancer. 2010; 103:1034-1039. DOI: 10.1038/sj.bjc.6605873 [PubMed: 20842116]

28. Scott R, Stone N, Kendall C, Geraki K, Rogers K. Relationships between pathology and crystal structure in breast calcifications: an in situ X-ray diffraction study in histological sections. Npj Breast Cancer. 2016; 2:16029.doi: 10.1038/npjbcancer.2016.29 [PubMed: 28721386]

29. Reznikov N, Shahar R, Weiner S. Bone hierarchical structure in three dimensions. Acta Biomater. 2014; 10:3815-3826. DOI: 10.1016/j.actbio.2014.05.024 [PubMed: 24914825]

30. Pleshko N, Boskey A, Mendelsohn R. Novel infrared spectroscopic method for the determination of crystallinity of hydroxyapatite minerals. Biophys J. 1991; 60:786-793. DOI: 10.1016/ S0006-3495(91)82113-0 [PubMed: 1660314]

31. Pathi SP, Lin DDW, Dorvee JR, Estroff LA, Fischbach C. Hydroxyapatite nanoparticle-containing scaffolds for the study of breast cancer bone metastasis. Biomaterials. 2011; 32:5112-5122. DOI: 10.1016/j.biomaterials.2011.03.055 [PubMed: 21507478]

32. Sadat-Shojai M, Khorasani MT, Dinpanah-Khoshdargi E, Jamshidi A. Synthesis methods for nanosized hydroxyapatite with diverse structures. Acta Biomater. 2013; 9:7591-7621. DOI: 10.1016/j.actbio.2013.04.012 [PubMed: 23583646]

33. Shi Z, Huang X, Cai Y, Tang R, Yang D. Size effect of hydroxyapatite nanoparticles on proliferation and apoptosis of osteoblast-like cells. Acta B. 2009; 5:338-345.

34. Liu ZS, Tang SL, Ai ZL. Effects of hydroxyapatite nanoparticles on proliferation and apoptosis of human hepatoma BEL-7402 cells. World J Gastroenterol. 2003; 9:1968-1971. [PubMed: 12970886]

35. Balasundaram G, Sato M, Webster TJ. Using hydroxyapatite nanoparticles and decreased crystallinity to promote osteoblast adhesion similar to functionalizing with RGD. Biomaterials. 2006; 27:2798-2805. DOI: 10.1016/j.biomaterials.2005.12.008 [PubMed: 16430957]

36. Kim K, Dean D, Lu A, Mikos AG, Fisher JP. Early osteogenic signal expression of rat bone marrow stromal cells is influenced by both hydroxyapatite nanoparticle content and initial cell seeding density in biodegradable nanocomposite scaffolds. Acta Biomater. 2011; 7:1249-64. DOI: 10.1016/j.actbio.2010.11.007 [PubMed: 21074640] 
37. Choi S, Coonrod S, Estroff LA, Fischbach C. Chemical and physical properties of carbonated hydroxyapatite affect breast cancer cell behavior. Acta Biomater. 2015; 24:333-342. DOI: 10.1016/j.actbio.2015.06.001 [PubMed: 26072364]

38. Liu AC, Joag VR, Gotlieb AI. The emerging role of valve interstitial cell phenotypes in regulating heart valve pathobiology. Am J Pathol. 2007; 171:1407-1418. DOI: 10.2353/ajpath.2007.070251 [PubMed: 17823281]

39. Richards J, El-Hamamsy I, Chen S, Sarang Z, Sarathchandra P, Yacoub MH, Chester AH, Butcher JT. Side-specific endothelial-dependent regulation of aortic valve calcification: interplay of hemodynamics and nitric oxide signaling. Am J Pathol. 2013; 182:1922-1931. DOI: 10.1016/ j.ajpath.2013.01.037 [PubMed: 23499458]

40. Boskey A, Mendelsohn R. Infrared analysis of bone in health and disease. J Biomed Opt. 2005; 10:31102.doi: 10.1117/1.1922927

41. Boskey AL, Goldberg M, Kulkarni A, Gomez S. Infrared imaging microscopy of bone: illustrations from a mouse model of Fabry disease. Biochim Biophys Acta. 2006; 1758:942-947. DOI: 10.1016/j.bbamem.2006.02.019 [PubMed: 16697974]

42. Taylor EA, Lloyd AA, Salazar-Lara C, Donnelly EL. Raman and FT-IR mineral to matrix ratios correlate with physical chemical properties of model compounds and native bone tissue. Appl Spectrosc. 2017; 3702817709286. doi: 10.1177/0003702817709286

43. Weiner S, Bar-Yosef O. States of preservation of bones from prehistoric sites in the Near East: A survey. J Archaeol Sci. 1990; 17:187-196. DOI: 10.1016/0305-4403(90)90058-D

44. Schindelin J, Arganda-Carreras I, Frise E, Kaynig V, Longair M, Pietzsch T, Preibisch S, Rueden C, Saalfeld S, Schmid B, Tinevez JY, White DJ, Hartenstein V, Eliceiri K, Tomancak P, Cardona A. Fiji: an open-source platform for biological-image analysis. Nat Methods. 2012; 9:676-682. DOI: 10.1038/nmeth.2019 [PubMed: 22743772]

45. Gould RA, Butcher JT. Isolation of valvular endothelial cells. J Vis Exp. 2010; :1-6. DOI: 10.3791/2158 [PubMed: 20164822]

46. Butcher JT, Nerem RM. Valvular endothelial cells regulate the phenotype of interstitial cells in coculture: effects of steady shear stress. Tissue Eng. 2006; 12:905-15. DOI: 10.1089/ten. 2006.12.905 [PubMed: 16674302]

47. Lievremont M, Potus J, Guillou B. Use of alizarin red S for histochemical staining of Ca2+ in the mouse; some parameters of the chemical reaction in vitro. Acta Anat. 1982; 114:268-80. [PubMed: 7158284]

48. Gregory CA, Gunn WG, Peister A, Prockop DJ. An Alizarin red-based assay of mineralization by adherent cells in culture: Comparison with cetylpyridinium chloride extraction. Anal Biochem. 2004; 329:77-84. DOI: 10.1016/j.ab.2004.02.002 [PubMed: 15136169]

49. Puchtler H, Meloan SN, Terry MS. On the history and mechanism of alizarin and alizarin red S stains for calcium. J Histochem Cytochem. 1969; 17:110-124. DOI: 10.1177/17.2.110 [PubMed: 4179464]

50. Mangialardo S, Cottignoli V, Cavarretta E, Salvador L, Postorino P, Maras A. Pathological biominerals: Raman and infrared studies of bioapatite deposits in human heart valves. Appl Spectrosc. 2012; 66:1121-1127. [PubMed: 23031694]

51. Boskey AL, Mendelsohn R. Infrared spectroscopic characterization of mineralized tissues. Vib Spectrosc. 2005; 38:107-114. DOI: 10.1016/j.vibspec.2005.02.015 [PubMed: 16691288]

52. Donnelly E, Meredith DS, Nguyen JT, Gladnick BP, Rebolledo BJ, Shaffer AD, Lorich DG, Lane JM, Boskey AL. Reduced cortical bone compositional heterogeneity with bisphosphonate treatment in postmenopausal women with intertrochanteric and subtrochanteric fractures. J Bone Miner Res. 2012; 27:672-678. DOI: 10.1002/jbmr.560 [PubMed: 22072397]

53. Termine JD, Posner AS. Infra-red determinaion of the percentage of crystallinity in apatitic calcium phosphates. Nature. 1966; 211:268-270. DOI: 10.1038/211268a0 [PubMed: 5965547]

54. Wu F, Lin DDW, Chang JH, Fischbach C, Estroff LA, Gourdon D. Effect of the materials properties of hydroxyapatite nanoparticles on fibronectin deposition and conformation. Cryst Growth Des. 2015; 15:2452-2460. DOI: 10.1021/acs.cgd.5b00231 
55. Dweck MR, Boon NA, Newby DE. Calcific aortic stenosis: a disease of the valve and the myocardium. J Am Coll Cardiol. 2012; 60:1854-1863. DOI: 10.1016/j.jacc.2012.02.093 [PubMed: 23062541]

56. Kim KM, Trump BF. Amorphous calcium precipitations in human aortic valve. Calcif Tissue Res. 1975; 18:155-160. [PubMed: 1148898]

57. Paschalis EP, DiCarlo E, Betts F, Sherman P, Mendelsohn R, Boskey AL. FTIR microspectroscopic analysis of human osteonal bone. Calcif Tissue Int. 1996; 59:480-487. DOI: 10.1007/ s002239900161 [PubMed: 8939775]

58. Gourion-Arsiquaud S, Lukashova L, Power J, Loveridge N, Reeve J, Boskey AL. Fourier transform infrared imaging of femoral neck bone: reduced heterogeneity of mineral-to-matrix and carbonateto-phosphate and more variable crystallinity in treatment-naive fracture cases compared with fracture-free controls. J Bone Miner Res. 2013; 28:150-161. DOI: 10.1002/jbmr.1724 [PubMed: 22865771]

59. Paschalis EP, Mendelsohn R, Boskey AL. Infrared assessment of bone quality: A review. Clin Orthop Relat Res. 2011; 469:2170-2178. DOI: 10.1007/s11999-010-1751-4 [PubMed: 21210314]

60. Bertazzo S, Gentleman E. Aortic valve calcification: a bone of contention. Eur Heart J. 2017; 38:1189-1193. DOI: 10.1093/eurheartj/ehw071 [PubMed: 26994153]

61. Boskey AL, Young MF, Kilts T, Verdelis K. Variation in mineral properties in normal and mutant bones and teeth. Cells Tissues Organs. 2006; 181:144-153. DOI: 10.1159/000091376

62. Li Z, Ai-Jawad M, Siddiqui S, Pasteris JD. A mineralogical study in contrasts: highly mineralized whale rostrum and human enamel. Sci Rep. 2015; 5:16511.doi: 10.1038/srep16511 [PubMed: 26552356]

63. van Engeland NCA, Bertazzo S, Sarathchandra P, McCormack A, Bouten CVC, Yacoub MH, Chester AH, Latif N. Aortic calcified particles modulate valvular endothelial and interstitial cells. Cardiovasc Pathol. 2017; 28:36-45. DOI: 10.1016/j.carpath.2017.02.006 [PubMed: 28319833]

64. Monzack EL, Masters KS. Can valvular interstitial cells become true osteoblasts? A side-by-side comparison. J Heart Valve Dis. 2011; 20:449-463. [PubMed: 21863660]

65. Kennedy JA, Hua X, Mishra K, Murphy GA, Rosenkranz AC, Horowitz JD. Inhibition of calcifying nodule formation in cultured porcine aortic valve cells by nitric oxide donors. Eur $\mathrm{J}$ Pharmacol. 2009; 602:28-35. DOI: 10.1016/j.ejphar.2008.11.029 [PubMed: 19056377]

66. Yip CYY, Chen JH, Zhao R, Simmons CA. Calcification by valve interstitial cells is regulated by the stiffness of the extracellular matrix. Arterioscler Thromb Vasc Biol. 2009; 29:936-942. DOI: 10.1161/ATVBAHA.108.182394 [PubMed: 19304575]

67. Jian B, Narula N, Li Q, Mohler E, Levy R. Progression of aortic valve stenosis: TGF-beta1 is present in calcified aortic valve cusps and promotes aortic valve interstitial cell calcification via apoptosis. Ann Thorac Surg. 2003; 72:457-465.

68. Cloyd KL, El-Hamamsy I, Boonrungsiman S, Hedegaard M, Gentleman E, Sarathchandra P, Colazzo F, Gentleman MM, Yacoub MH, Chester AH, Stevens MM. Characterization of porcine aortic valvular interstitial cell "calcified" nodules. PLoS One. 2012; 7:1-9. DOI: 10.1371/ journal.pone.0048154

69. Kim KM. Apoptosis and calcification. Scanning Microsc. 1995; 9:1137-1178. [PubMed: 8819895]

70. Mohler ER. Mechanisms of aortic valve calcification. Am J Cardiol. 2004; 94:1396-1402, A6. DOI: 10.1016/j.amjcard.2004.08.013 [PubMed: 15566910]

71. Fisher CI, Chen J, Merryman WD. Calcific nodule morphogenesis by heart valve interstitial cells is strain dependent. Biomech Model Mechanobiol. 2013; 12:5-17. DOI: 10.1007/s10237-012-0377-8 [PubMed: 22307683]

72. Maeno S, Niki Y, Matsumoto H, Morioka H, Yatabe T, Funayama A, Toyama Y, Taguchi T, Tanaka J. The effect of calcium ion concentration on osteoblast viability, proliferation and differentiation in monolayer and 3D culture. Biomaterials. 2005; 26:4847-4855. [PubMed: 15763264]

73. Turkez H, Yousef M, Sonmez E, Togar B, Bakan F, Sozio P, Stefano A. Evaluation of cytotoxic, oxidative stress and genotoxic responses of hydroxyapatite nanoparticles on human blood cells. J Appl Toxicol. 2013; 34:373-379. [PubMed: 24474238] 
74. Sonmez E, Cacciatore I, Bakan F, Turkez H, Mohtar Y, Togar B, Stefano A. Toxicity assessment of hydroxyapatite nanoparticles in rate liver cell model in vitro. Hum Exp Toxicol. 2016; 35:10731083. [PubMed: 26655636]

75. Chen L, Mccrate JM, Lee JCM, Li H. The role of surface charge on the uptake and biocompatibility of hydroxyapatite nanoparticles with osteoblast cells. Nanotechnology. 2011; 22:105708.doi: 10.1088/0957-4484/22/10/105708 [PubMed: 21289408]

76. Kafshgari MH, Harding FJ, Voelcker NH. Insights into Cellular Uptake of Nanoparticles. Curr Drug Deliv. 2015; 12:63-77. [PubMed: 25146441]

77. Xu JL, Khor KA, Sui JJ, Zhang JH, Chen WN. Protein expression profiles in osteoblasts in response to differentially shaped hydroxyapatite nanoparticles. Biomaterials. 2009; 30:5385-5391. DOI: 10.1016/j.biomaterials.2009.07.002 [PubMed: 19631375]

78. Wu F, Chen W, Gillis B, Fischbach C, Estroff LA, Gourdon D. Protein-crystal interface mediates cell adhesion and proangiogenic secretion. Biomaterials. 2017; 116:174-185. DOI: 10.1016/ j.biomaterials.2016.11.043 [PubMed: 27940370]

79. Liu X, Sun J. Potential proinflammatory effects of hydroxyapatite nanoparticles on endothelial cells in a monocyte - endothelial cell coculture model. Int J Nanomedicine. 2014; 9:1261-1273. [PubMed: 24648726]

80. Wang XF, Lu PJ, Song Y, Sun YC, Wang YG, Wang Y. Nano hydroxyapatite particles promote osteogenesis in a three-dimensional bio-printing construct consisting of alginate/gelatin/hASCs. RSC Adv. 2016; 6:6832-6842.

81. Shi Z, Huang X, Cai Y, Tang R, Yang D. Size effect of hydroxyapatite nanoparticles on proliferation and apoptosis of osteoblast-like cells. Acta Biomater. 2009; 5:338-345. DOI: 10.1016/j.actbio.2008.07.023 [PubMed: 18753024]

82. Otto CM, Prendergast B. Aortic-valve stenosis - from patients at risk to severe valve obstruction. N Engl J Med. 2014; 371:744-756. DOI: 10.1056/NEJMra1313875 [PubMed: 25140960] 


\section{Statement of significance}

We implement a 3D in vitro platform with embedded hydroxyapatite (HA) nanoparticles to investigate the interaction between valve interstitial cells, valve endothelial cells, and a mineral-rich extracellular environment. HA nanoparticles were synthesized based on analysis of the mineral properties of calcific regions of diseased human aortic valves. Our findings indicate that crystallinity of HA drives activation and differentiation in interstitial and endothelial cells. We also show that a mineralized environment blocks endothelial protection against interstitial cell calcification. Our HA-containing hydrogel model provides a unique 3D platform to evaluate valve cell responses to a mineralized ECM. This study additionally lays the groundwork to capture the diversity of mineral properties in calcified valves, and link these properties to progression of the disease. 
A
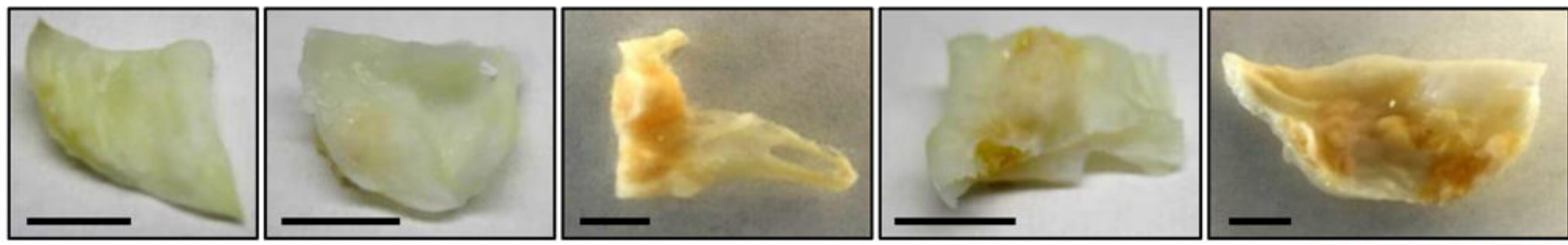

Scale $=5 \mathrm{~mm}$
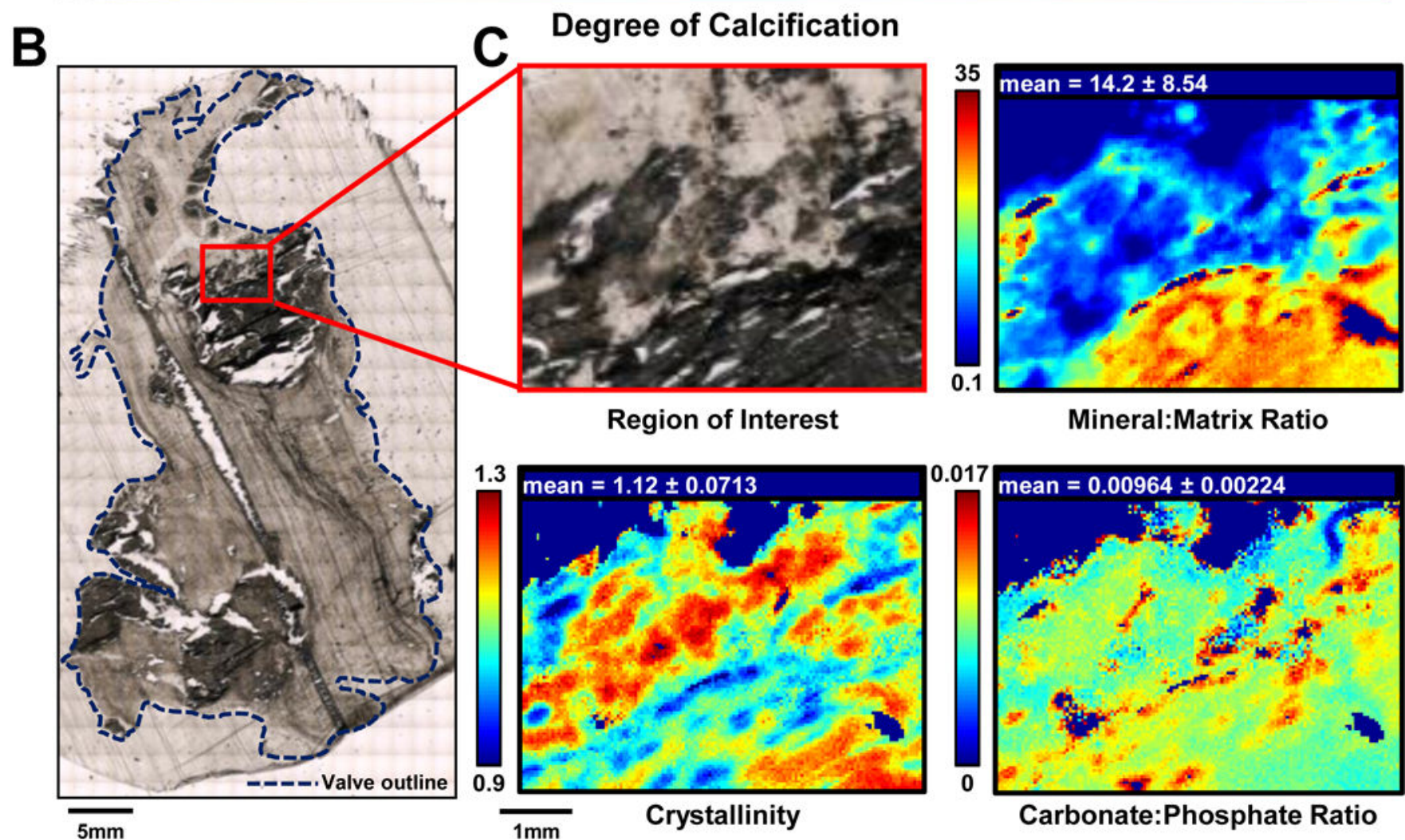

Carbonate:Phosphate Ratio

Figure 1.

A) Human aortic valves with increasing severity of calcification, $n=5$. B) White light image of a PMMA-embedded section taken from the most calcified valve (area ratio of calcification $=0.624)$, with region of interest indicated (red box). C) White light image from the calcified region of interest and corresponding FTIR images for mineral:matrix ratio (area ratio of the phosphate $\mathrm{v}_{1}\left[900-1200 \mathrm{~cm}^{-1}\right]$ and amide $\mathrm{I}\left[1585-1720 \mathrm{~cm}^{-1}\right]$ peaks), crystallinity (intensity ratio of $1030 \mathrm{~cm}^{-1}$ and $1020 \mathrm{~cm}^{-1}$ bands), and carbonate:phosphate ratio (area ratio of the carbonate $\mathrm{v}_{2}\left(840-892 \mathrm{~cm}^{-1}\right)$ and phosphate $\left.\mathrm{v}_{1}\right)$. FTIR parameter means are indicated. 

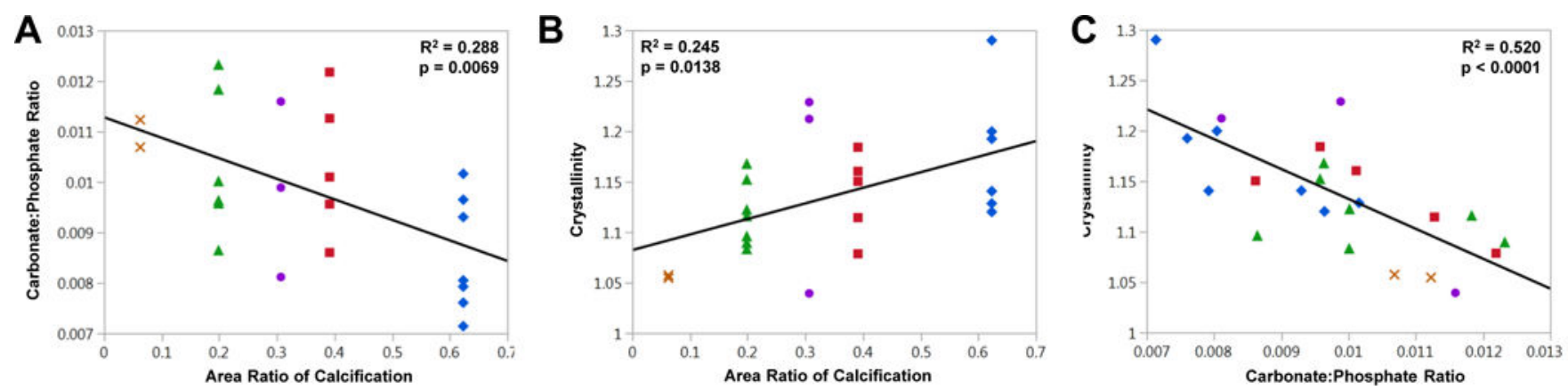

Figure 2.

Trends in FTIR mineral parameters. Regressions with best fit line for A) carbonate:phosphate vs. area ratio of calcification, B) crystallinity vs. area ratio of calcification, and C) crystallinity vs. carbonate:phosphate ratio. Area ratio of calcification is defined as the area of calcified lesions divided by the total area of the valve. $n=2-7$ ROI's per valve leaflet (5 leaflets total, each symbol represents a different valve) 


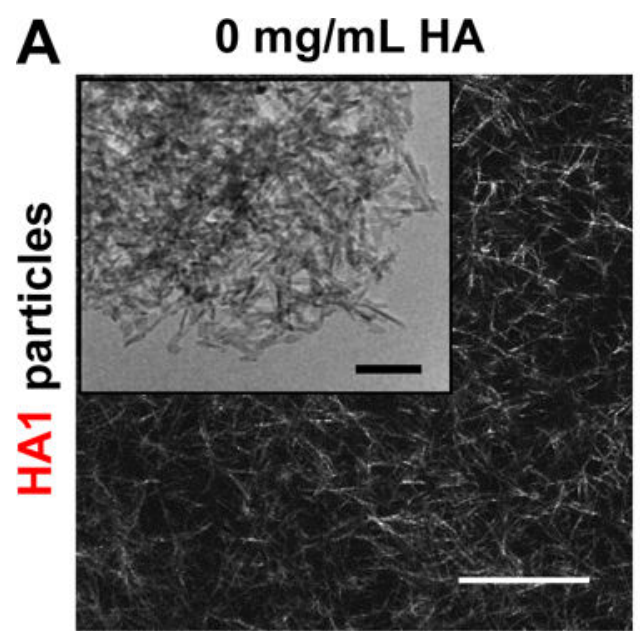

$0.1 \mathrm{mg} / \mathrm{mL}$ HA

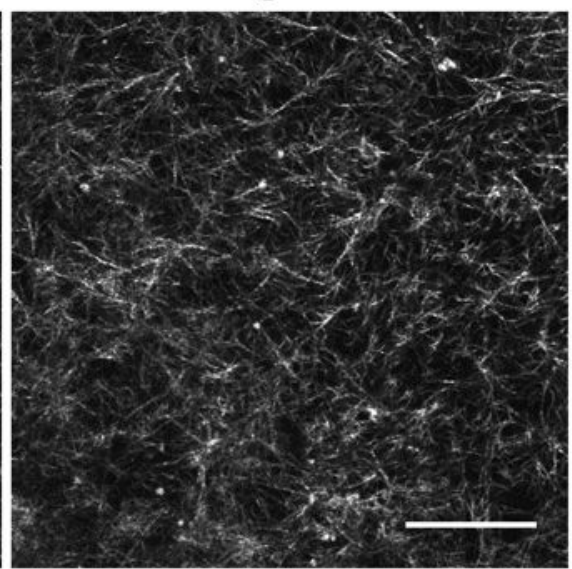

B

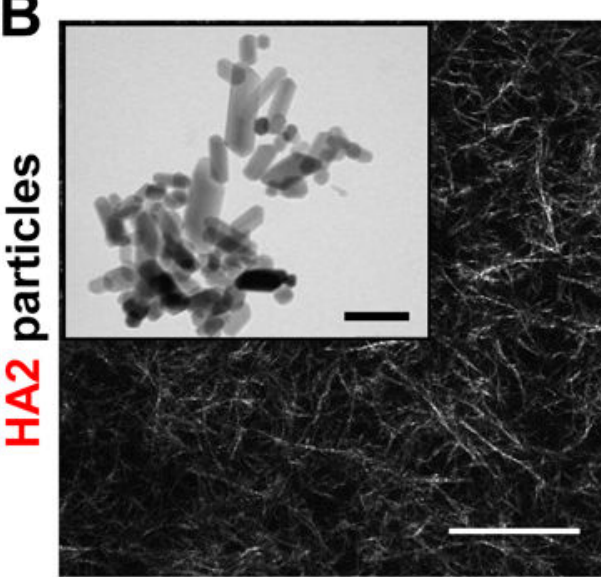

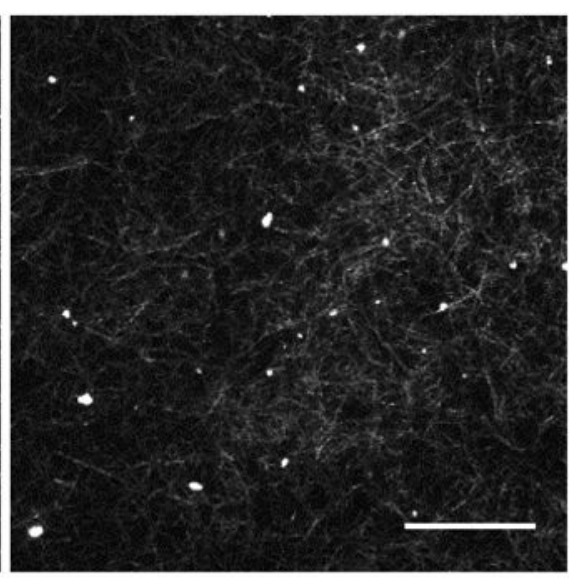

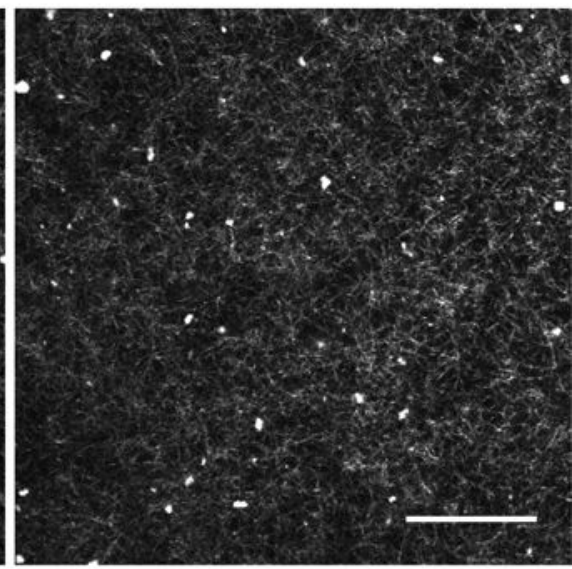

$0.25 \mathrm{mg} / \mathrm{mL}$ HA

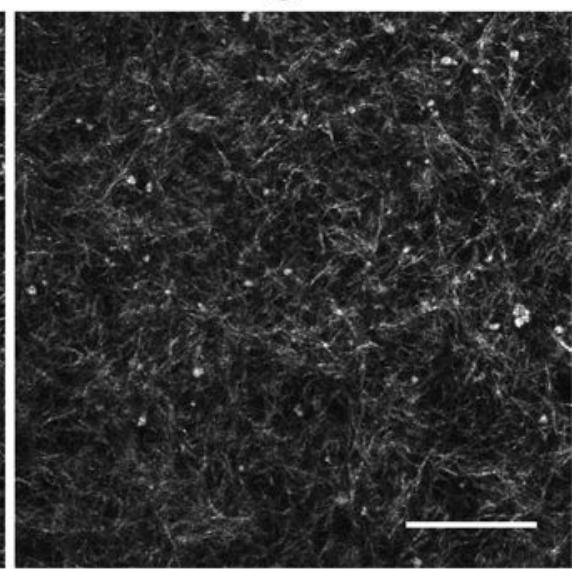

Scale bar $=50 \mu \mathrm{m}$, inset scale bar $=100 \mathrm{~nm}$

Figure 3.

Incorporation of poorly crystalline (HA1) and crystalline (HA2) HA particles into collagen gels. A) Representative images of the distribution of less crystalline HA1 particle aggregates within collagen gels, visualized via reflectance imaging. Scale bars $=50 \mu \mathrm{m}$. Inset: TEM image of dialyzed HA1 particles. Scale bar: $100 \mathrm{~nm}$. B) Distribution of more crystalline HA2 particle aggregates within collagen gels, visualized via reflectance imaging. Scale bar $=50 \mu \mathrm{m}$. Inset: TEM image of dialyzed HA2 particles. Scale bar $=100 \mathrm{~nm}$. 

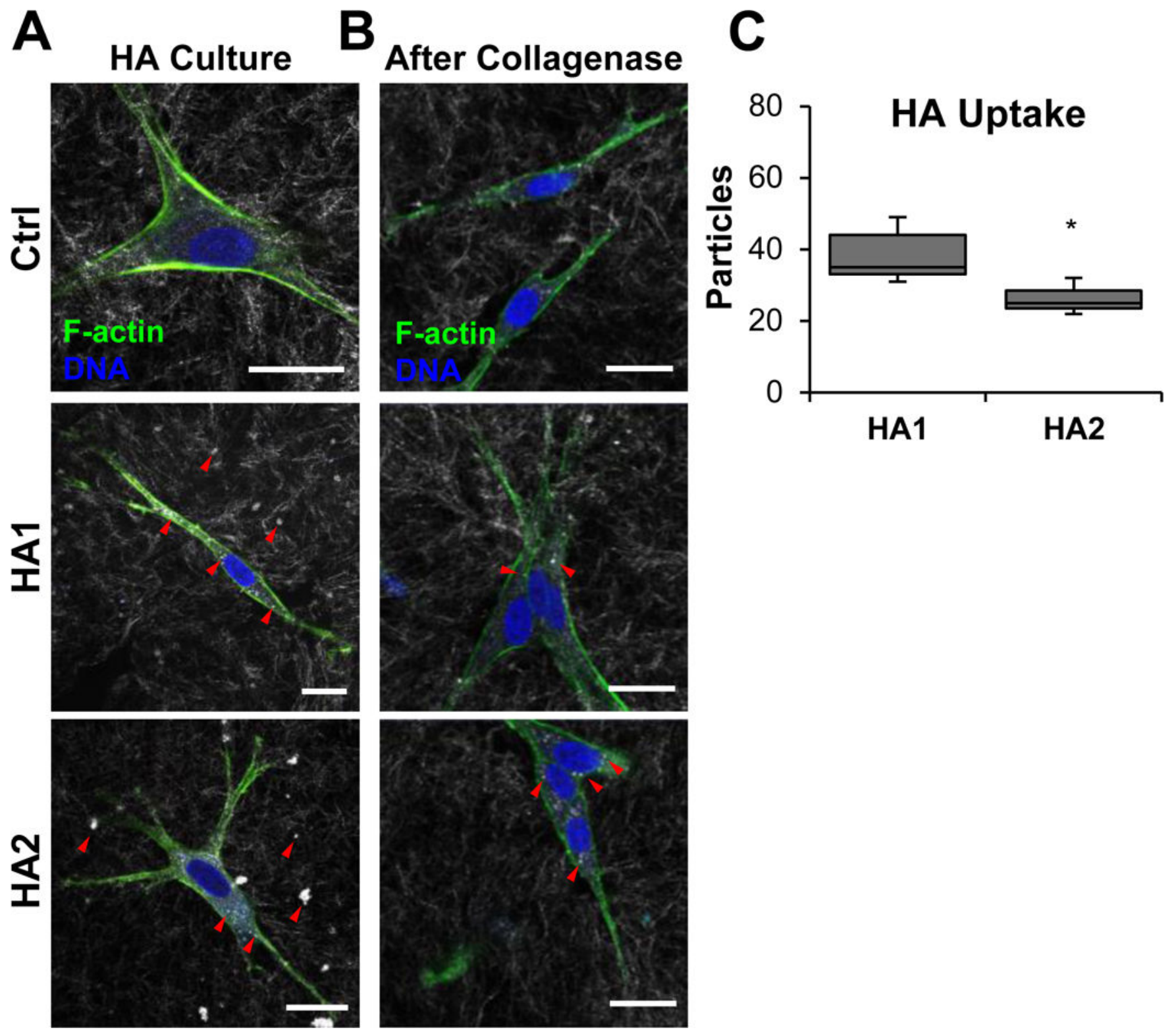

Figure 4.

VIC uptake of HA aggregates. A) HA particle aggregates in and around VIC seeded within an HA-rich gel. B) HA particle aggregates within VIC after collagen digestion and centrifugation, followed by re-seeding in HA-free collagen gels. Scale bars $=20 \mu \mathrm{m}$. C) VIC uptake of HA particles is greater in less crystalline HA gels. Values are expressed as means $\pm \mathrm{SEM}, * p<0.05, \mathrm{n}=5$. 

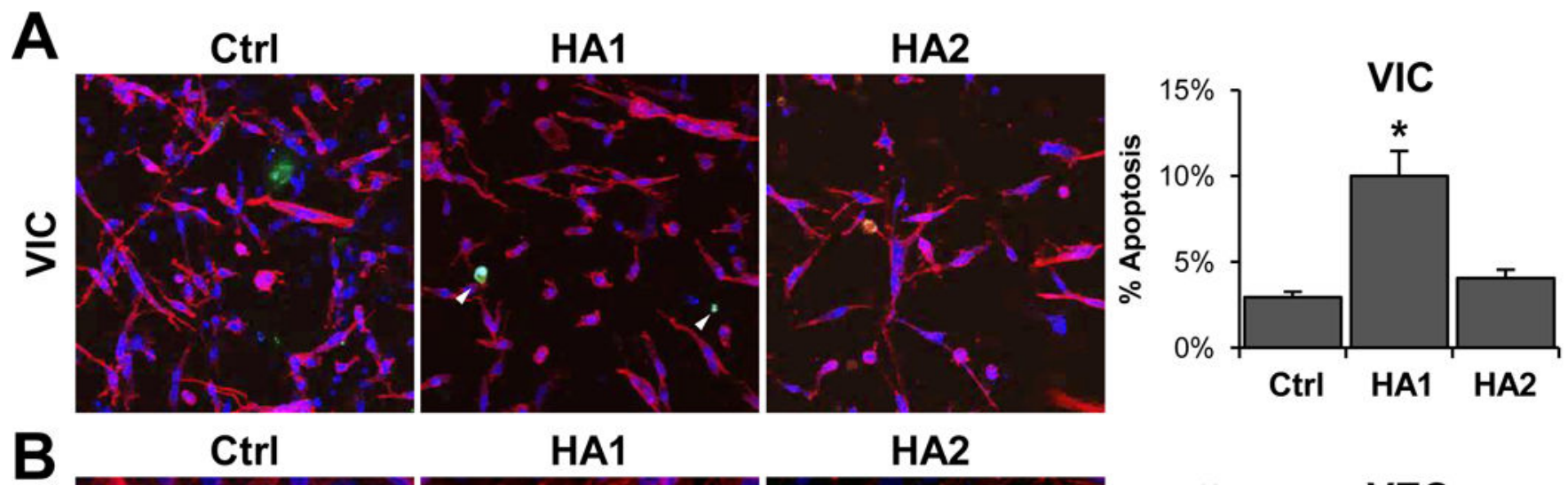

Ctrl

HA1

HA2
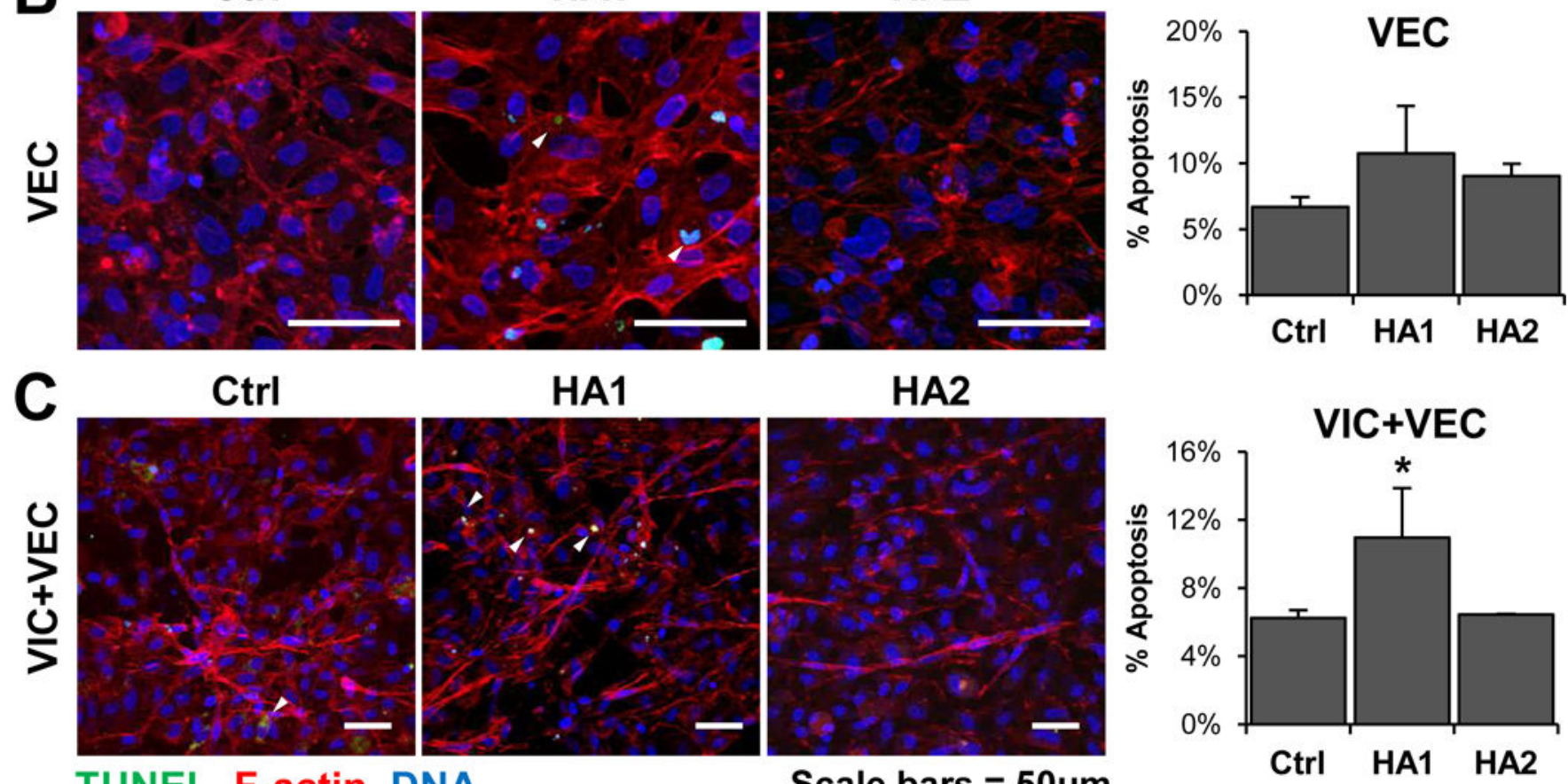

TUNEL, F-actin, DNA

Scale bars $=50 \mu \mathrm{m}$

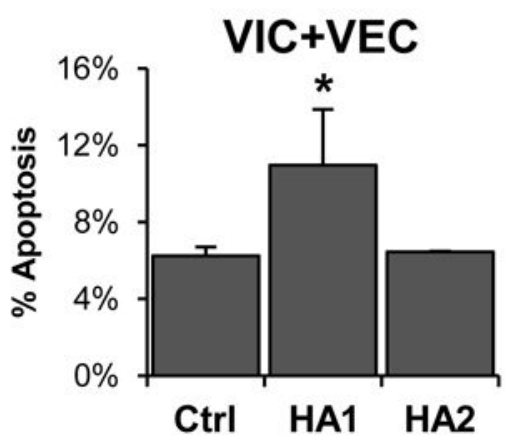

Figure 5.

Apoptosis of HA particle-incorporated collagen gels. TUNEL staining of A) VIC-only, B) VEC-only and C) VIC+VEC co-cultures with or without HA particles. \% Apoptosis is shown with TUNEL and expressed as a ratio of TUNEL-positive cells over total cells. Scale bars $=50 \mu \mathrm{m}$. Values are expressed as means \pm SEM, $* p<0.05, n=4$. 

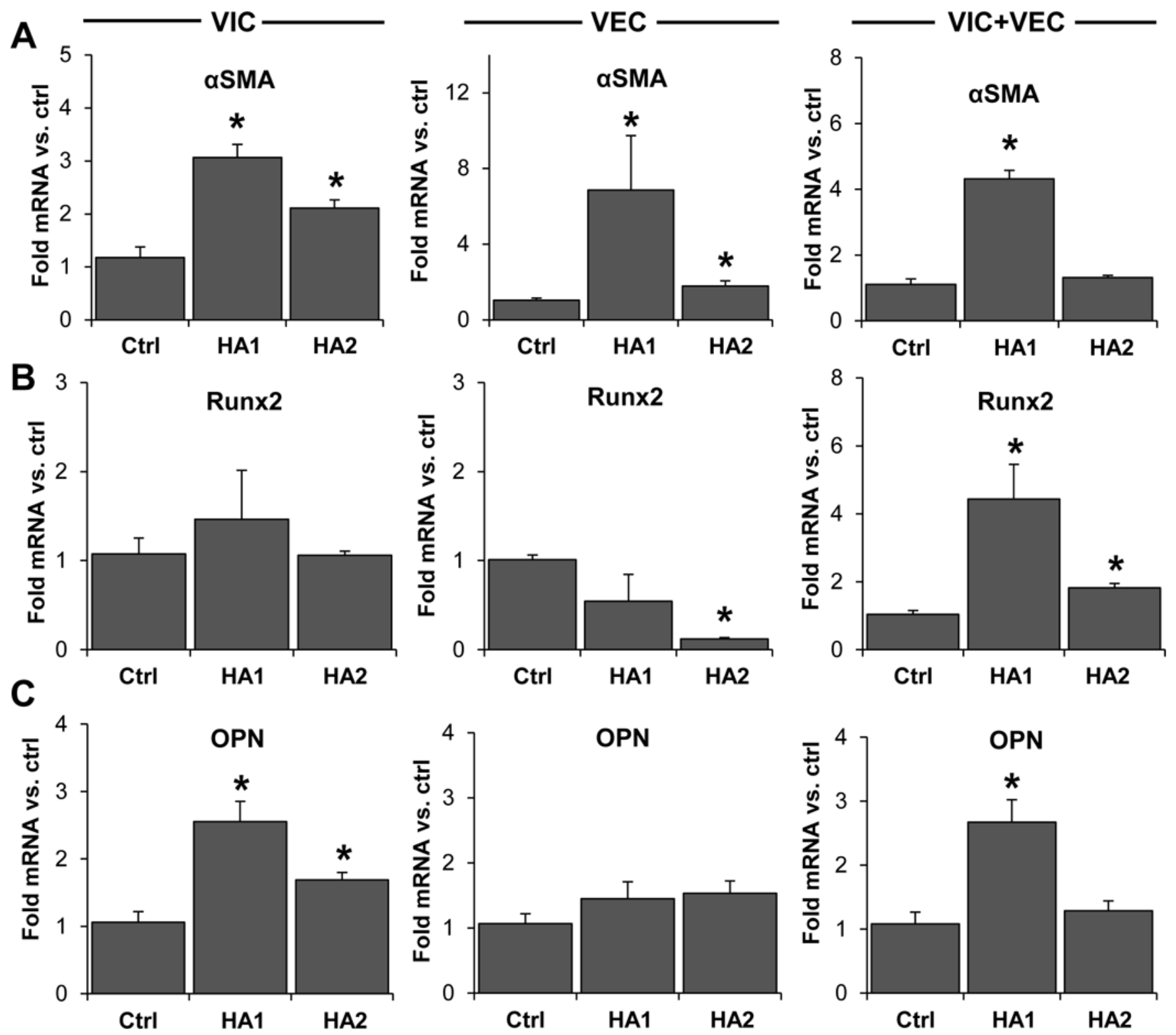

Figure 6.

Real-time PCR shows effect of less crystalline HA1 and more crystalline HA2 particles on the expression of A) aSMA (Acta2), B) Runx2, and C) osteopontin in VIC-only, VEC-only and VIC+VEC co-culture gels. Values are expressed as fold changes and are means $\pm \mathrm{SEM}$, $* p<0.05, n=4$. 

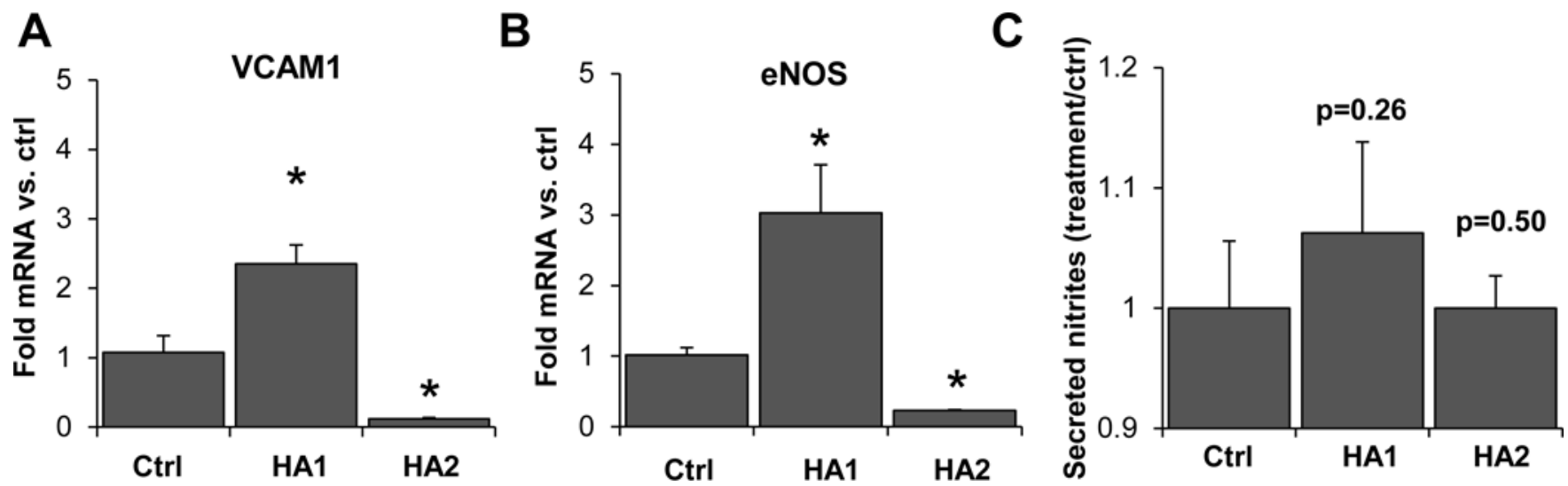

Figure 7.

VEC activity in co-cultures with HA particles. Real-time PCR shows effect of less crystalline HA1 and more crystalline HA2 particles on the expression of A) VCAM1 and B) eNOS. C) Nitrite secretion (indirect measure of nitric oxide) was higher for co-cultures with less crystalline HA1 particles, although differences were not statistically significant. Values are expressed as fold changes and are means \pm SEM, $* p<0.05, n=4$. 

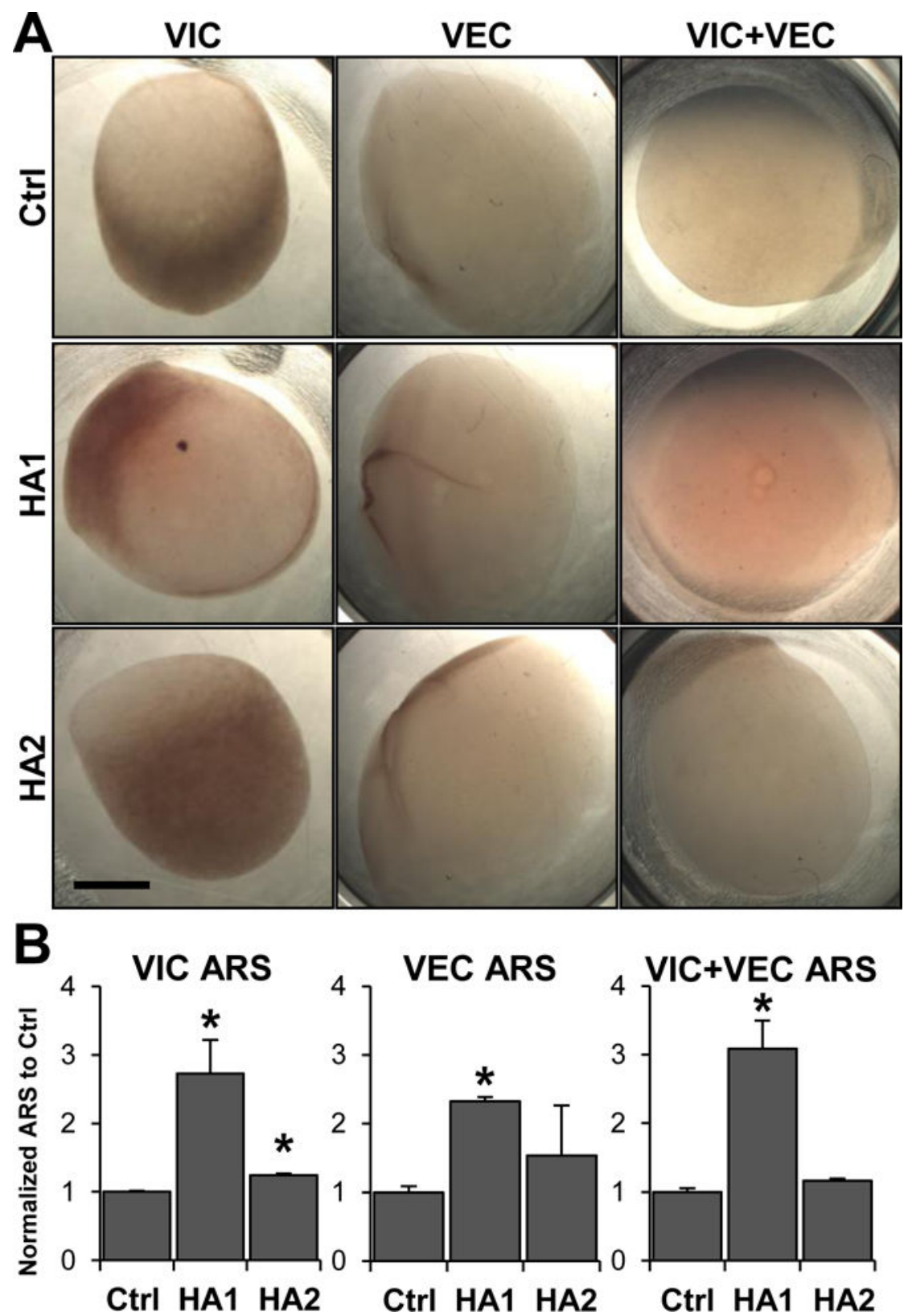

Figure 8.

Matrix-bound calcium in HA-incorporated collagen gel constructs. (A) Representative images of VIC, VEC, and VIC+VEC HA1- and HA2-containing gels stained with Alizarin Red S (ARS). (B) Quantification of matrix-bound calcium via ARS analysis in VIC, VEC, and VIC+VEC HA-incorporated gels. Amount of ARS detected is normalized to cell-free control gels. Scale bar $=3 \mathrm{~mm}$. Values are expressed as means $\pm \mathrm{SEM}, * p<0.05, n=4$. 